Review

\title{
Buy or make? Agricultural production diversity, markets and dietary diversity in Afghanistan
}

\author{
Giacomo Zanello $^{\mathrm{a}, *}$, Bhavani Shankar ${ }^{\mathrm{b}}$, Nigel Poole ${ }^{\mathrm{b}}$

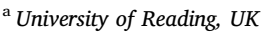 \\ ${ }^{\mathrm{b}}$ SOAS University of London, UK
}

\section{A R T I C L E I N F O}

\section{Keywords:}

Dietary diversity

Nutrition

Agricultural production diversity

Food markets

Seasonality

Afghanistan

\begin{abstract}
A B S T R A C T
Increasing on-farm production diversity and improving markets are recognized as ways to improve the dietary diversity of smallholders. Using instrumental variable methods to account for endogeneity, we study the interplay of production diversity, markets and diets in the context of seasonality in Afghanistan. We confirm an important seasonal dimension to the interplay. Improved crop diversity over the year is positively associated with dietary diversity in the regular season, but not in the lean season. Livestock species diversity remains important for dietary diversity throughout the year, but particularly so in the lean season when the influence of cropping diversity is low. Market aspects become important for dietary diversity specifically in the lean season.
\end{abstract}

\section{Introduction}

Inadequate nutrition significantly constrains human welfare in many parts of the developing world, and in particular in the poorest areas of South Asia. Maternal and child malnutrition has important implications for mortality, morbidity and productivity (Black et al., 2013). The cost of undernutrition in adults in Asia and Africa has recently been estimated at 8-11\% of GDP (IFPRI, 2015). In recognition of its global importance as a development outcome, improved nutrition has been explicitly incorporated into Sustainable Development Goal (SDG) 2, "End hunger, achieve food security and improved nutrition and promote sustainable agriculture". Nutrition is also of fundamental importance in achieving SDG goals in several other areas including health, education, and inequality (IFPRI, 2015).

Food intake is fundamental to nutrition, although several other factors also contribute and combine in complex ways to determine nutritional status. There is now widespread recognition that those consuming more diverse diets are less likely to be deficient in the range of nutrients that are essential for optimal human functioning (Arimond and Ruel, 2004; Smith and Haddad, 2015). Dietary diversity and quality have been shown to be important to improving nutrition outcomes ranging from anthropometrics to iron deficiency anaemia (Arimond and Ruel, 2004; Balarajan et al., 2011).

Accordingly, the nutrition programming community has devised strategies to improve dietary diversity in deficient populations. Given the livelihoods of a large proportion of those suffering from undernutrition are agriculture-based, the 'agriculture for nutrition' agenda that has emerged over the last decade has emphasised the development of interventions promoting greater farm-level production diversity, such as home gardens and livestock donations. Such interventions aim to impact dietary diversity of rural producers by introducing new farm enterprises involving nutritious foods and encouraging own consumption from production and income from sales (Olney et al., 2009; Rawlins et al., 2014).

An academic literature (reviewed below) has also emerged that proposes that farm-level production diversity is important to household dietary diversity in rural areas of developing countries. Recently this literature has begun to debate the relative importance of markets in comparison to on-farm production diversity for the diversification of diets. Given that well-functioning markets are a pre-requisite for the income pathway to dietary diversification and may be critical to food provisioning even in areas characterised by subsistence agriculture, it would seem important to study the role of markets in enabling dietary diversity. This may also have important policy and programming implications - whilst the current focus tends to be on developing additional production enterprises such as home gardens, greater recognition of the importance of markets may suggest investment in developing transport infrastructure and market facilities.

There is, however, an important nuance that is currently largely missing in this debate, and this concerns seasonality. Agricultural production, market interactions and food availability in developing countries are frequently marked by strong seasonal variation. There is

\footnotetext{
* Corresponding author at: School of Agriculture Policy and Development, University of Reading, Early Gate, Whiteknights Road, RG6 6AR Reading, UK.

E-mail addresses: g.zanello@reading.ac.uk (G. Zanello), b.shankar@soas.ac.uk (B. Shankar), n.poole@soas.ac.uk (N. Poole).
} 
potential for seasonal change in the relative importance of markets and own-production in providing dietary diversity, but limited consideration has been given this in the literature. In this paper, we advance the literature on the relative importance of markets versus own-production in providing dietary diversity by considering the interplay between own-production and markets in the context of seasonality. Additionally, we enable a richer characterisation of the role of food markets than the previous literature. Data considerations typically limit the characterisation of market sourcing of nutrition to measures such as the household's distance from market. It is plausible that the diversity of foods available in markets is important to market sourcing of dietary diversity, just as production diversity is argued to be important to on-farm sourcing of dietary diversity.

Our setting is Afghanistan, where agricultural production is markedly seasonal, with a lengthy winter lean period when agricultural production possibilities are severely limited by snow and extreme cold. Additionally, difficult terrain, conflict, and poor infrastructure create the pre-conditions for variability in market food availability, making the central questions investigated in this paper particularly important. Agriculture is central to Afghan livelihoods: $80 \%$ of the total population and $90 \%$ of the poor live in rural areas and $40 \%$ of employment is in agriculture (World Bank, 2014). Afghanistan also has a poor nutrition profile - summary results from a National Nutrition Survey conducted in 2013 show that under-5 stunting prevalence is $41 \%$ nationally and up to $70 \%$ in the worst provinces (Ministry of Public Health and UNICEF, 2013). Micronutrient malnutrition is a serious problem in the country, with iron and vitamin-A deficiencies being particularly widespread (Levitt et al., 2011; Flores-Martinez et al., 2016). Public strategies to address malnutrition have tended to be more 'therapeutic' supplementation rather than food-based developmental approaches to re-orientate agricultural production and wider sectoral policies in a pronutrition direction (Poole et al., 2016). Thus, Afghanistan provides an ideal setting for investigating the research questions posed by this work.

\section{Previous literature}

Over the last decade, interest has been growing in research questions about how the agriculture sector can contribute to better nutrition outcomes (Turner et al., 2013). Given the importance of agriculture for the livelihoods of populations in low-income countries, the nutrition of agricultural producers has been a particular focus. A literature has developed that specifically examines whether the diversity of species grown on farm contributes to dietary diversity of farm households. Where markets function smoothly, production and consumption decisions of farm households are completely separable (Singh et al., 1986). Where markets work well, production diversity can only impact dietary diversity if it boosts income and thereby demand for diverse diets. However, market failure is a common feature of low-income countries, and high transactions costs in accessing markets imply that subsistence production is commonplace (Taylor and Adelman, 2003). In such circumstances, farm-level production diversity can be hypothesised to have a direct linkage with dietary diversity.

A series of papers has empirically examined the links between production diversity and dietary diversity at the household/individual level. This literature has generally found that increased production diversity has a positive influence on dietary diversity (Jones et al., 2014; Hirvonen and Hoddinott, 2017; Sibhatu et al., 2015a; Kumar, Harris and Rawat, 2015; Dillon et al., 2015; Koppmair et al., 2017). ${ }^{1}$ A study set in Malawi (Jones et al., 2014) found that while production diversity

\footnotetext{
${ }^{1}$ We restrict our literature review to the production and dietary diversity linkage, since that is our immediate focus. We do not review research attempting to link production diversity with anthropometric outcomes such as child height-for-age, nor studies analysing linkages between specific production enterprises, e.g. cattle or sheep, and nutrition outcomes.
}

has a positive association with dietary diversity, more subsistence-oriented households have lower dietary diversity even after controlling for wealth. This suggests that diverse, market-oriented production may also operate through an income pathway to improved diet quality. On the other hand, a study drawing on data from four countries (Sibhatu et al., 2015a) suggested that, where production diversity is already high, further increases may reduce income gains from specialisation and thereby reduce dietary diversity.

This literature has also acknowledged the importance of markets to dietary diversity. Markets help generate income from farm production and thereby increase effective household demand for diet quality, and also supply a diversity of foods to satisfy that demand. Generally, greater market access/orientation has been found to improve dietary diversity. Based upon the relative sizes of coefficients relating to market access and production diversity, Sibhatu et al. (2015a) concluded that market access is more important than production diversity for improving dietary diversity. On this basis they argued that too much emphasis should not be placed on increasing on-farm dietary diversity, and that greater consideration should be given to improving market access. This has sparked a debate, with Remans et al. (2015) arguing that strengthening market access can be difficult in some settings, and thus encouraging production diversity at landscape or district level is still important, and Sibhatu et al. (2015b) responding that market access is important to fighting both undernutrition as well as poverty in remote areas.

This is an important debate with significant programming and policy implications. However, the characterisation of the role of seasonality in this literature has been limited. Agricultural production, market access, food availability in the market and consumption are all potentially highly susceptible to seasonal influences, particularly in low-income country settings. However, analysis of seasonality, which once comprised a dynamic research area, has received relatively little attention in recent years (Hirvonen et al., 2016; Devereux et al., 2013). The small recent literature on seasonality in dietary diversity (mostly set in Africa) shows mixed results - for example, Becquey et al. (2012) found that diet quality in urban areas of Burkina Faso worsens in the agricultural lean season compared to the regular season, while Hirvonen et al. (2016) found dietary diversity in their Ethiopian sample to be relatively high in the lean season. In a similar setting, Sibhatu and Qaim (2017) found that across seasons purchased foods have a larger contribution to dietary diversity than own production. Even in settings where households find mechanisms to maintain diversity of diets across seasons, it would be valuable to know what those mechanisms are. For example, do markets play a bigger role in diet quality improvement in lean compared to the post-harvest season? How does the role of crop versus livestock species diversity in influencing dietary diversity change across seasons? In this paper, we are able to address this dimension largely lacking in the previous literature with the help of dietary diversity data collected throughout the year and data on food market availability across the seasons.

Another contribution we make to the literature is to provide a richer characterisation of markets as a source of food. The role of markets has been captured in this literature using variables relating to market orientation of producers (e.g. proportion of food consumed from own production (Jones et al., 2014)), production diversity in the community (Kumar et al., 2015) and market access (e.g. distance from market (Sibhatu et al., 2015a; Hirvonen and Hoddinott, 2017)). However, markets in low-income countries range can vary tremendously, ranging from tiny makeshift facilities to substantial wet markets. This can result in significant variation in the variety of foods available and the choice sets from which households can build their consumption bundles and dietary diversity. Furthermore, the availability of foods in local markets is subject to significant change across seasons. Capturing such variability in market food availability is important to informing this debate. There is a well-established literature in high-income countries linking local food availability in supermarkets and other retail outlets to 
overnutrition and unhealthy diets (Caspi et al., 2012). However, such detailed consideration of local food availability is generally missing in the literature considering diet quality in low-income country situations. In this paper, although we lack market food availability information directly within the primary dataset we use, we are able to match and merge district-level information on the market availability of different foods across the seasons from another dataset. This enables us to explicitly consider the linkage between market food availability and dietary diversity by season.

\section{Setting}

\subsection{Agriculture}

Agriculture provides a source of income for almost $45 \%$ of Afghani households, and for more than a third of households it is the most important income source (Central Statistics Organisation, 2016). Most farm households operate between 1 and 2 ha of land. Operated land is more commonly irrigated than rainfed. Wheat is by far the most important crop in Afghanistan and is generally planted in October/November and harvested between May and July. The second tier of important crops, maize, rice and pulses, are harvested in the late summer or autumn, as is cotton, a key cash crop. Some vegetables and tubers, including the significant potato crop, are harvested in the spring. Livestock keeping is very important, and ownership of cattle, sheep, goats and chicken is commonplace. Sixty per cent of all households hold livestock, in comparison to $55 \%$ with access to land. Twelve per cent of households own a garden plot, which is an important source of fruits, nuts and vegetables (Central Statistics Organisation, 2016). Depending on the geographical area, the lean season falls sometime between December and April, when wintry conditions prevail that are frequently severe. Little active cultivation takes place in the lean season and roads may become impassable, particularly at higher altitudes.

\subsection{Diets}

The Afghan diet is dominated by wheat (flour), and Afghanistan is among the highest per capita consumers of wheat in the world (FloresMartinez et al., 2016). In 2011-12, cereals and tubers provided $67 \%$ of mean calorie intake, with oils and fats contributing $13 \%$, animal source foods and pulses $11 \%$, and fruit and vegetables $4 \%$ (Central Statistics Organization, 2014). Households consume cereals, mostly wheat flour, on a daily basis and in large quantities. Milk consumption is widespread and relatively frequent, with households consuming dairy foods 2.3 days a week on average. Meat consumption takes place 1.3 times a week, while vegetables and fruit are consumed twice a week on average (Central Statistics Organisation, 2016). Significant micronutrient deficiencies in Afghanistan include iron and vitamin-A (Ministry of Public Health and UNICEF, 2013).

\section{Data}

Our primary source of data is the Afghanistan Living Condition Survey 2013-14 (ALCS). For part of our analysis, we supplement the ALCS data with market food availability information from the National Risk and Vulnerability Assessment 2011-12 (NRVA) survey dataset. Both data sources are part of the local and international effort in tracking the recovery progress of Afghanistan after decades of instability and violence. They are nationally as well as regionally representative cross-sectional household surveys of the living standards with samples of almost 21,000 households each undertaken by the Central Statistics Organization of Afghanistan. Household selection was based on a stratified sampling procedure with a two-stage cluster design per stratum (Central Statistics Organisation, 2016). In both surveys, data collection was spread throughout the year with a view to making the data seasonally representative. ${ }^{2}$

Out of a full sample of 20,778 households surveyed in the ALCS, in this study we use a sub-sample of 14,079 households that are engaged in at least one agricultural production activity (either livestock or crop). ${ }^{3}$ The vast majority of these households live in rural areas (90\%) and are located in 324 districts spread over all 34 provinces in Afghanistan. In addition to a 13-section household questionnaire covering aspects such as agricultural production and household assets, the ALCS includes separate male and female modules probing specific areas where either the household head or their spouse was the main decisionmaker. Included in the female module is seven-day recall information on the household consumption of foods consumed. The data on agricultural production refers to the previous agricultural season, while consumption information is based on a 7-day recall at the time of the survey. In addition to household information, data were also collected at community (Shura) level, addressing topics including community facilities, projects and development priorities. The survey included 1870 Shura.

The ALCS is the successor of the NRVA and both surveys have a substantial intersection with regard to survey design and instruments. However, there are critical differences that compelled us to merge information from the two datasets for part of the analysis reported here. On the one hand, the NRVA questionnaire did not collect household consumption information using a validated Food Consumption Survey questionnaire, preventing us from building an accurate dietary diversity indicator using the NRVA data. On the other hand, the ALCS questionnaire did not collect any information on market food availability, while the NRVA did. For most of our analysis, we use the ALCS dataset alone, relying on its household-level measurement of diets, agricultural production, market access, and numerous socio-economic variables. In the last stage of our empirical analysis, we supplement this with district-level aggregation of information on market food availability from the NRVA. A feature that enables us to confidently use this strategy is that market food availability information collected in the NRVA did not relate to a specific year, but instead queried typical availability of specific foods in local (community) markets throughout the year. For each food item the respondents indicated the local food availability (abundant, moderate or not at all) in each month. Although the market food availability data were collected at Shura (community) level, the communities were anonymised, precluding us from matching at that level. We therefore aggregated market food availability information up to district level, identifying and merging information on a total of 386 of 398 districts. Shuras within districts tend to be relatively homogenous - for example, within-district variance in market food availability data in the NRVA was relatively low - and on average each district is represented by six Shuras (S.D. $=5.2$ ).

\subsection{Measurement of production diversity}

Our primary measures of diversity in production activities are separate counts of crop $^{4}$ and livestock species grown or raised by the household in the year. Previous research has used crop counts only

\footnotetext{
${ }^{2}$ Due to local security issues the seasonal representation was not consistent in a small number of the provinces. For example, in 19\% of the sampled districts in the ALCS fewer interviews were conducted than originally planned. To address this issue, the weighted distribution was smoothed to ensure that the estimated population size by quarter is the same (Central Statistics Organisation, 2016), enabling us to integrate in our analysis the seasonality component.

${ }^{3}$ For the purpose of this study we have also excluded from our analysis the Kuchi, nomadic pastoralists that represented two percent of the total households surveyed.

${ }^{4}$ The questionnaire design does not allow us to identify the size of each plot, and thus it is not possible to construct indices that take into account both richness (number of crops) and evenness (distribution of area cultivated) of crop production, such as Simpson's Index (Jones et al., 2014).
} 
(Herforth, 2010; Meng et al., 1998) or a 'production diversity' index that presents an aggregate count of crop plus livestock species (Jones et al., 2014; Sibhatu et al., 2015a). We use separate counts since the separate influences of crop and livestock diversity across seasons are potentially interesting to investigate. As a robustness check, we also present results from using an aggregate production diversity index.

\subsection{Market access and food availability}

Empirical studies that have investigated the contribution of markets to household dietary diversity have mainly captured this effect via markets access variables such as the presence of market in the community or distance of households from the market (Hoddinott et al., 2015; Jones et al., 2014; Sibhatu et al., 2015). In our estimates we use a more granular indicator of market access, viz. the cost of transporting a $50 \mathrm{~kg}$ of wheat to the nearest market. This proxies not just the distance to the market, but also captures the quality of the road infrastructure and the competitiveness of local transport companies. It summarises the proportional transaction cost of market participation.

In characterizing the market dimension in this research, we go beyond geographical market access to additionally capturing the varying availability of specific foods in the market across the year. As discussed above, this is done by merging in district-level information on market food availability from the NRVA. The NRVA dataset records the availability of food in each Shura market for each month (0 being 'not available', $1=$ 'moderately available', and $2=$ 'abundantly available') of nine key food items (bread, fresh fruit, dried fruit, chicken, lamb, dried meat, milk/dairy, fresh veg, rice). These are the most commonly consumed food items in the setting and make up $78 \%$ of the weight of the Food Consumption Score, the main dietary diversity measure used in this study. Based on this information, we create an index that captures the average food availability in the market during the month in which the households were surveyed. The index is the mean of the availability of the 11 food items, ranging from 0 (no food items available at all at the market) to 2 (every food item abundantly available at the market). This community-level index is then aggregated at the district level using a simple mean of community-level index values. Thus, the district-level Market Food Availability Index (MFAI) provides a snapshot of the regional availability of a basket of food items that make up a large proportion of diets of local households, measured at the time at which the respondents were surveyed. However, it is not without its limitations, for example the lack of availability of pulses in the index. Moreover, we assume that market food availability as expressed by respondents in the NRVA in 2011 applies at the time of the ALCS in 2013, and that the district-level aggregation we apply is appropriate.

\subsection{Measurement of dietary diversity}

Our principal measure of household dietary diversity is the Food Consumption Score (FCS), a weighted score calculated using the frequency of consumption of different food groups consumed by a household during the 7 days before the survey (Kennedy et al., 2011). The ALCS survey used an FCS-validated questionnaire (WFP, 2008) for dietary data collection, enabling us to construct the measure robustly. The food groups, with the respective weights based on the energy, protein and micronutrient densities, include main staples (2), pulses (3), vegetables (1), fruits (1), meat and fish (4), milk (4), sugar (0.5), oil $(0.5)$, and condiments $(0)$. The constructed FCS is a continuous variable taking values between 0 and 112 .

\subsection{Measurement of seasonality}

In Afghanistan the main harvest period is generally between May and July for main staples including winter wheat, maize and winter barley crops. Spring wheat and rice are also cultivated and are harvested later, in August-September, and October-November respectively. The main post-harvest period can extend from August to midDecember, and the pre-harvest (the lean season) is generally from midDecember to April. However, due to different climatic conditions across geographical areas, there is wide variability in seasonal agricultural patterns in Afghanistan. For example, the lean season can range from two months in some areas (e.g. Kunar and Nangarhar) to six months for the provinces in the Central Highlands and the north-east (Badakhshan). To capture this heterogeneity, for each of the 34 Provinces we identified a regular and lean season based on the seasonal crop calendar reported in Central Statistics Organisation (2014). ${ }^{5}$

\section{Methods}

Our empirical specification can be motivated by a nonseparable household model that directly connects agricultural production aspects to household consumption. Specifically, we refer to the exposition of Dillon et al. (2015), who present a dynamic specification drawing upon the work of Behrman (1997) and LaFave et al. (2013). Under this specification, agricultural households maximise expected utility arising from consumption of own-produced food $C^{\text {own }}$ goods purchased from the market $C^{\text {market }}$ and leisure $l$.

Households choose consumption vectors, farm inputs and leisure to maximise $\sum_{t=0}^{\infty} \beta^{t} \mathrm{U}\left(C_{t}^{\text {Own }}, C_{t}^{\text {market }}, l_{t}\right)$ subject to an agricultural production function that specifies output as a function of inputs including household labour; a labour equation specifying that total labour endowment is spent on on-farm and off-farm labour and leisure; and an intertemporal budget constraint where budget endowment in $(t+1)$ depends upon budget endowment, farm profits and returns to labour in $t$.

Under nonseparability, consumption choice manifestations $C_{t}$ such as dietary diversity are directly influenced by production factors. We can generally write $C_{t}=f(\boldsymbol{P}, \boldsymbol{Y}, \boldsymbol{I}, \boldsymbol{H})$. Here, $\boldsymbol{P}$ is a vector of prices, including market prices (and transaction costs), food prices, input prices and interest rates. $\boldsymbol{Y}$ denotes agricultural production factors, $\boldsymbol{I}$ captures exogenous income and $\boldsymbol{H}$ represents household characteristics influencing preferences. We assume that prices unobserved in the data are captured by province fixed effects.

We estimate a series of regressions that model dietary diversity as a function of production diversity, market variables as well as a set of other covariates that have been found relevant in previous literature. The models share the same set of covariates:

$y=\beta_{0}+\beta_{1} \boldsymbol{A}+\beta_{2} \boldsymbol{B}+\beta_{3} \boldsymbol{C}+\beta_{4} \boldsymbol{D}+\varepsilon$.

Our dependent variable ( $y$ ) captures FCS. The focus of the analysis is on the vector $\mathbf{A}$, which contains measures of production diversity, a measure of market access/infrastructure (i.e. cost of transporting $50 \mathrm{~kg}$ of wheat to the local market), and in later specifications, the Market Food Availability Index (MFAI). Each of these variables is then interacted with a dummy variable capturing lean season to capture the effect of seasonality. Household characteristics are captured in the vector $\mathbf{B}$. Sociodemographic characteristics contained in $\mathbf{B}$ include the age of the household head and whether $\mathrm{s} /$ he is literate, the number of males, females, elderly, and children in the household, whether the household was surveyed during Ramadan or during the lean season (the latter is used when the sample is not split by season), and the urban/rural status. Vector $\mathbf{C}$ consists of a wealth index based on the ownership of a set of assets built using a principal components analysis as described in Rutstein and Kiersten (2004). We also control for regional differences and remoteness by including dummies for the 34 provinces of Afghanistan (to capture climate heterogeneity and unobserved prices differences) and whether the household lives in a valley in vector $\mathbf{D}$. Regressions are population weighted and standard errors clustered at

\footnotetext{
${ }^{5}$ The seasonal crop calendar is reported In Table A (Appendix).
} 
Shura level to account for the substantial heterogeneity in the sample.

\subsection{Instrumental variable approach}

Household dietary diversity is influenced by a multitude of factors, some of which may not be observed or fully captured in our dataset. These unobserved household factors may drive both production as well as dietary diversity and the correlation between these factors and production diversity can result in biased estimation. For example, farmers' attitudes and aptitudes may jointly affect both production diversity and dietary diversity, but we are not able to observe and capture these characteristics. The literature in this area has addressed the endogeneity problem with different degrees of sophistication, ranging from disregarding the issue (Jones et al., 2014; Koppmair et al., 2017; Sibhatu et al., 2015) to Instrumental Variables (IV) strategies (Dillon et al., 2015; Hirvonen and Hoddinott, 2017). Sibhatu and Qaim (2018) review the literature linking farm production diversity with dietary diversity and nutrition. They note that, out of the several studies in the literature, only Hirvonen and Hoddinott (2017) and Dillon et al. (2015) implement IV strategies to enable robust causal identification. They also note that seasonality is seldom explicitly addressed in this literature, a lacuna that we attempt to fill.

To improve causal identification in this context, we too use an IV procedure. A valid instrument must be exogenous, correlated with production diversity but plausibly not correlated with dietary diversity, except for the indirect effect through production diversity. Our initial strategy attempted to collate information on rainfall, average temperatures, and characteristics of the terrain (soil type and slope) for use as instruments (Hirvonen and Hoddinott, 2017). However, lack of availability of suitable data for Afghanistan prevented the implementation of this strategy. Since ALCS does not collect GPS coordinates to locate the households or Shuras, the smallest identifiable units in the data are districts. The limited number of districts together with the wide range of climates and terrain covered by some of them (several districts cover both valleys and high peaks) did not allow satisfactory identification.

Instead, we implement an alternative strategy, instrumenting crop and livestock diversity indices with the averages of crop and livestock diversity indices respectively of neighbours in the community, defined as households living in the same Shura. This strategy draws inspiration from recent work on irrigation use in agriculture (Li and Zhao, 2018), and impacts of supermarkets on farm household nutrition in Kenya (Chege et al., 2015), where information on irrigation status and access to supermarkets of neighbours are respectively used to instrument own irrigation and supermarket access. This is consistent with the literature on herd behaviour and neighbourhood effects (Holloway et al., 2002) in agriculture with peer-to-peer learning influencing decisions such as the on-farm enterprise mix.

Shuras are composed of elected Community Development Councils (CDCs) and represent the smallest administrative units in Afghanistan. Traditionally established as customary councils led by elders, the role of Shuras have developed to represent local issues (often at village level) to the Provincial and Central governments (Nixon, 2008). An average of 7.6 households were sampled per Shura in the ALCS dataset $(S D=1.84)$. We exploit such granularity in our data to strengthen the identification strategy and exogeneity of the instrument.

There validity of using neighbours' crop and livestock diversity as an instrument could be called into question by (a) neighbour's production diversity influencing barter/gifts and thereby affecting a household's dietary diversity; and (b) neighbour's production diversity influencing food supply in local markets, and thereby influencing an household's dietary diversity. ${ }^{6}$ On the barter/gifts aspect, we can throw some light using the data we have regarding the way in which each food

\footnotetext{
${ }^{6}$ We are thankful to a reviewer for pointing this out specifically.
}

Table 1

Summary statistics.

\begin{tabular}{|c|c|c|c|c|c|c|}
\hline & \multicolumn{2}{|c|}{ Afghanistan } & \multicolumn{2}{|l|}{ Rural } & \multicolumn{2}{|l|}{ Urban } \\
\hline & Mean & SD & Mean & SD & Mean & SD \\
\hline \multicolumn{7}{|l|}{ Diet and diet diversity } \\
\hline Food Consumption Score (FCS) & 40.50 & 15.50 & 40.24 & 15.42 & 43.07 & 16.09 \\
\hline FCS from own production & 14.84 & 15.33 & 15.88 & 15.38 & 4.61 & 10.26 \\
\hline FCS from purchases (market) & 24.28 & 13.19 & 22.94 & 12.20 & 37.56 & 15.17 \\
\hline $\begin{array}{l}\text { FCS from other sources (gifts } \\
\text { and aid) }\end{array}$ & 1.37 & 4.76 & 1.42 & 4.83 & 0.90 & 3.90 \\
\hline \multicolumn{7}{|l|}{ Farm and market characteristics } \\
\hline Crop Diversity Index (CDI) & 1.36 & 1.20 & 1.46 & 1.19 & 0.39 & 0.80 \\
\hline Livestock Diversity Index (LDI) & 1.97 & 1.16 & 2.04 & 1.17 & 1.27 & 0.80 \\
\hline $\begin{array}{l}\text { Market Food Availability Index } \\
\quad \text { (MFAI) }\end{array}$ & 0.91 & 0.44 & 0.88 & 0.43 & 1.20 & 0.47 \\
\hline $\begin{array}{l}\text { Transport cost of } 50 \mathrm{Kg} \text { of wheat } \\
\text { to market (ANF) }\end{array}$ & 43.54 & 98.85 & 47.52 & 101.72 & 4.24 & 48.70 \\
\hline Urban (dummy) & 0.09 & 0.29 & & & . & \\
\hline Located in a valley (dummy) & 0.13 & 0.34 & 0.14 & 0.35 & 0.04 & 0.19 \\
\hline Total land cultivated (acres) & 5.25 & 13.49 & 5.52 & 13.25 & 2.51 & 15.45 \\
\hline \multicolumn{7}{|l|}{ Household characteristics } \\
\hline $\begin{array}{l}\text { Household head literate } \\
\text { (dummy) }\end{array}$ & 0.33 & 0.47 & 0.32 & 0.47 & 0.45 & 0.50 \\
\hline Age of household head & 44.00 & 14.21 & 43.65 & 14.18 & 47.51 & 14.03 \\
\hline $\begin{array}{l}\text { Num. of males in the household } \\
\text { (10-64 yo) }\end{array}$ & 2.34 & 1.46 & 2.29 & 1.43 & 2.80 & 1.69 \\
\hline $\begin{array}{l}\text { Num. of females in the } \\
\text { household (10-64 yo) }\end{array}$ & 2.27 & 1.33 & 2.23 & 1.31 & 2.62 & 1.46 \\
\hline $\begin{array}{l}\text { Num. of children in the } \\
\text { household }(<10 \text { yo })\end{array}$ & 3.30 & 2.17 & 3.34 & 2.16 & 2.96 & 2.20 \\
\hline $\begin{array}{l}\text { Num. of elderly in the } \\
\text { household ( }>64 \text { yo) }\end{array}$ & 0.20 & 0.47 & 0.19 & 0.46 & 0.28 & 0.53 \\
\hline Wealth index & 0.07 & 0.25 & 0.07 & 0.25 & 0.07 & 0.26 \\
\hline $\begin{array}{l}\text { Interviewed during Ramadan } \\
\text { (dummy) }\end{array}$ & 0.30 & 0.46 & 0.31 & 0.46 & 0.22 & 0.41 \\
\hline Lean season (dummy) & 0.33 & 0.47 & 0.32 & 0.47 & 0.45 & 0.50 \\
\hline Sample size & 14,079 & & 13,183 & & 896 & \\
\hline
\end{tabular}

Note: Population weighted means.

was acquired. The dataset records the source of each food as 'own produced', 'market purchased' and 'gifts/exchange'. However, the percentage of foods obtained via person-to-person exchange was very low in the dataset $(<4 \%)$. Thus there is some evidence to suggest that the gifts/barter aspect is minor does not influence the validity of the instrument. On the neighbour's production diversity influencing greater availability of foods in the market, it is worth noting that in our second set of results, the IV estimate is conditional on market food availability, albeit at the district level. Although only at a higher level of aggregation, we thus have some conditioning on market food availability in our analysis which potentially reduces this concern. ${ }^{7}$

For each estimated model, we report the results of Durbin-WuHausman endogeneity tests and tests of instruments robustness (Wald test based on Stock and Yogo significance levels). It is worth noting at this point that we do recognise that the validity of our identification strategy as sketched above is debatable, and therefore caution is warranted in making firm causal conclusions from our analysis.

\footnotetext{
${ }^{7}$ As an additional robustness check, we also implemented an alternative IV regression using extension visits as an instrumental variable. The ALCS questionnaire includes two variables capturing whether the household was visited by an agriculture extension service for crop and livestock farming activities separately. Visits by extension agents are plausibly correlated with production diversity, but are unlikely to be related to dietary diversity other than through production channels. Results are broadly consistent with the chosen instrument and reported in an Online Appendix.
} 
Table 2

Food composition score, by groups.

\begin{tabular}{llll}
\hline & Full sample & Regular season & Lean season \\
\hline Poor & $24 \%$ & $24 \%$ & $26 \%$ \\
Borderline & $32 \%$ & $32 \%$ & $34 \%$ \\
Acceptable & $43 \%$ & $44 \%$ & $40 \%$
\end{tabular}

Note: Population weighted means.

\section{Results}

\subsection{Descriptive statistics}

Tables 1-5 provide summary descriptions of the sample.

Table 1 shows summary statistics for the main variables, for Afghanistan as a whole, as well as for rural and urban households specifically. A striking fact that emerges from Table 1 is that the Food Consumption Score from market purchase is much larger than the FCS from own production. About $60 \%$ of dietary diversity as measured by the FCS derives from the market, as compared to only about $35 \%$ from own production. Thus, even in a low-income setting, with problems associated with difficult terrain and poor infrastructure, markets provide the bulk of dietary diversity. Not surprisingly, this gap is even larger in urban areas where only $11 \%$ of the FCS derives from own production. However, even in rural areas of Afghanistan, markets account for $57 \%$ of average FCS.

Table 2 shows that, applying the WFP cut-offs (WFP, 2008) for acceptable FCS, a quarter of Afghan households are classified as having poor diets, while another $32 \%$ have 'borderline' diets. A surprising revelation from Table 2 is that there appears to be limited variation in the quality of diets across seasons. There is only a marginal increase in poor and borderline diets in the lean season compared to post-harvest. Thus, Afghan households appear to be successfully smoothing diets across

Table 3

Proportions of households engaging in specific production enterprises.

\begin{tabular}{|c|c|c|c|c|c|c|c|c|}
\hline & Cereals & Pulses & Vegetables & Fruits & Cash crop & Livestock & Milk & Other \\
\hline National & $59 \%$ & $5 \%$ & $14 \%$ & $14 \%$ & $3 \%$ & $90 \%$ & $77 \%$ & $13 \%$ \\
\hline
\end{tabular}

Note: Population weighted means. Cash crops include cotton, flax, cumin, and sugar cane. Livestock include only livestock raised for food (cattle, goats, sheep, chickens and other birds). Milk refers to the ownership of milk animals, and is captured by the ownership of female cattle, goats and sheep of reproductive age. Other crops include alfalfa, opium, and an unidentified 'other crops'.

Table 4

Consumption and sourcing by season.

\begin{tabular}{|c|c|c|c|c|c|c|c|c|c|c|c|c|c|c|c|c|c|c|}
\hline & \multicolumn{3}{|c|}{ Cereals } & \multicolumn{3}{|c|}{ Pulses } & \multicolumn{3}{|c|}{ Vegetables } & \multicolumn{3}{|l|}{ Fruits } & \multicolumn{3}{|c|}{ Meat and Fish } & \multicolumn{3}{|l|}{ Milk } \\
\hline & Tot. & Own & Mkt. & Tot. & Own & Mkt. & Tot. & Own & Mkt. & Tot. & Own & Mkt. & Tot. & Own & Mkt. & Tot. & Own & Mkt. \\
\hline \multicolumn{19}{|l|}{ National } \\
\hline Full Sample & $100 \%$ & $32 \%$ & $67 \%$ & $63 \%$ & $4 \%$ & $57 \%$ & $58 \%$ & $9 \%$ & $46 \%$ & $41 \%$ & $7 \%$ & $32 \%$ & $67 \%$ & $17 \%$ & $47 \%$ & $67 \%$ & $45 \%$ & $16 \%$ \\
\hline Regular Season & $100 \%$ & $32 \%$ & $67 \%$ & $62 \%$ & $4 \%$ & $56 \%$ & $61 \%$ & $10 \%$ & $48 \%$ & $44 \%$ & $8 \%$ & $33 \%$ & $66 \%$ & $17 \%$ & $46 \%$ & $68 \%$ & $46 \%$ & $15 \%$ \\
\hline Lean Season & $100 \%$ & $32 \%$ & $68 \%$ & $66 \%$ & $4 \%$ & $60 \%$ & $51 \%$ & $6 \%$ & $40 \%$ & $34 \%$ & $4 \%$ & $28 \%$ & $68 \%$ & $17 \%$ & $49 \%$ & $63 \%$ & $42 \%$ & $17 \%$ \\
\hline \multicolumn{19}{|l|}{ Rural } \\
\hline Full Sample & $100 \%$ & $35 \%$ & $65 \%$ & $62 \%$ & $4 \%$ & $55 \%$ & $56 \%$ & $9 \%$ & $42 \%$ & $39 \%$ & $7 \%$ & $29 \%$ & $65 \%$ & $18 \%$ & $45 \%$ & $67 \%$ & $48 \%$ & $13 \%$ \\
\hline Regular Season & $100 \%$ & $35 \%$ & $64 \%$ & $60 \%$ & $4 \%$ & $54 \%$ & $59 \%$ & $10 \%$ & $44 \%$ & $41 \%$ & $8 \%$ & $30 \%$ & $65 \%$ & $18 \%$ & $44 \%$ & $69 \%$ & $50 \%$ & $12 \%$ \\
\hline Lean Season & $100 \%$ & $32 \%$ & $68 \%$ & $66 \%$ & $4 \%$ & $60 \%$ & $51 \%$ & $6 \%$ & $40 \%$ & $34 \%$ & $4 \%$ & $28 \%$ & $68 \%$ & $17 \%$ & $49 \%$ & $63 \%$ & $42 \%$ & $17 \%$ \\
\hline \multicolumn{19}{|l|}{ Urban } \\
\hline Full Sample & $100 \%$ & $6 \%$ & $93 \%$ & $79 \%$ & $1 \%$ & $77 \%$ & $82 \%$ & $4 \%$ & $76 \%$ & $61 \%$ & $3 \%$ & $56 \%$ & $79 \%$ & $6 \%$ & $70 \%$ & $63 \%$ & $14 \%$ & $47 \%$ \\
\hline Regular Season & $100 \%$ & $6 \%$ & $93 \%$ & $79 \%$ & $1 \%$ & $77 \%$ & $84 \%$ & $4 \%$ & $78 \%$ & $64 \%$ & $3 \%$ & $59 \%$ & $79 \%$ & $6 \%$ & $70 \%$ & $66 \%$ & $15 \%$ & $49 \%$ \\
\hline Lean Season & $100 \%$ & $6 \%$ & $93 \%$ & $79 \%$ & $0 \%$ & $77 \%$ & $75 \%$ & $1 \%$ & $71 \%$ & $50 \%$ & $1 \%$ & $48 \%$ & $81 \%$ & $7 \%$ & $73 \%$ & $54 \%$ & $10 \%$ & $40 \%$ \\
\hline
\end{tabular}

Note: Population weighted means.

Table 5

Market food availability, by location and season.

\begin{tabular}{|c|c|c|c|c|c|c|c|c|c|}
\hline & Bread & Fresh fruit & Dried fruit & Chicken & Lamb & Dried meat & Milk/Dairy & Fresh veg & Rice \\
\hline \multicolumn{10}{|l|}{ National } \\
\hline Full Sample & $96 \%$ & $50 \%$ & $50 \%$ & $71 \%$ & $69 \%$ & $22 \%$ & $72 \%$ & $53 \%$ & $82 \%$ \\
\hline Regular Season & $97 \%$ & $60 \%$ & $47 \%$ & $72 \%$ & $71 \%$ & $14 \%$ & $79 \%$ & $62 \%$ & $83 \%$ \\
\hline Lean Season & $95 \%$ & $28 \%$ & $58 \%$ & $69 \%$ & $64 \%$ & $42 \%$ & $55 \%$ & $33 \%$ & $80 \%$ \\
\hline \multicolumn{10}{|l|}{ Rural } \\
\hline Full Sample & $96 \%$ & $48 \%$ & $49 \%$ & $68 \%$ & $67 \%$ & $23 \%$ & $71 \%$ & $51 \%$ & $81 \%$ \\
\hline Regular Season & $97 \%$ & $58 \%$ & $45 \%$ & $69 \%$ & $69 \%$ & $14 \%$ & $78 \%$ & $60 \%$ & $82 \%$ \\
\hline Lean Season & $95 \%$ & $26 \%$ & $57 \%$ & $67 \%$ & $63 \%$ & $42 \%$ & $54 \%$ & $31 \%$ & $79 \%$ \\
\hline \multicolumn{10}{|l|}{ Urban } \\
\hline Full Sample & $98 \%$ & $69 \%$ & $67 \%$ & $94 \%$ & $87 \%$ & $18 \%$ & $81 \%$ & $70 \%$ & $93 \%$ \\
\hline Regular Season & $98 \%$ & $74 \%$ & $68 \%$ & $95 \%$ & $90 \%$ & $10 \%$ & $84 \%$ & $75 \%$ & $93 \%$ \\
\hline Lean Season & $98 \%$ & $54 \%$ & $61 \%$ & $88 \%$ & $77 \%$ & $44 \%$ & $70 \%$ & $54 \%$ & $93 \%$ \\
\hline
\end{tabular}

Note: Sample including households engaged in any agricultural production activity. Market availability of each food items is based at Shura market and monthly recorded ( 0 being 'not available', $1=$ 'moderately' or 'abundantly' available). Data refer to typical availability (i.e. not for a specific year) but were collected as part of NRVA 2011-12. 


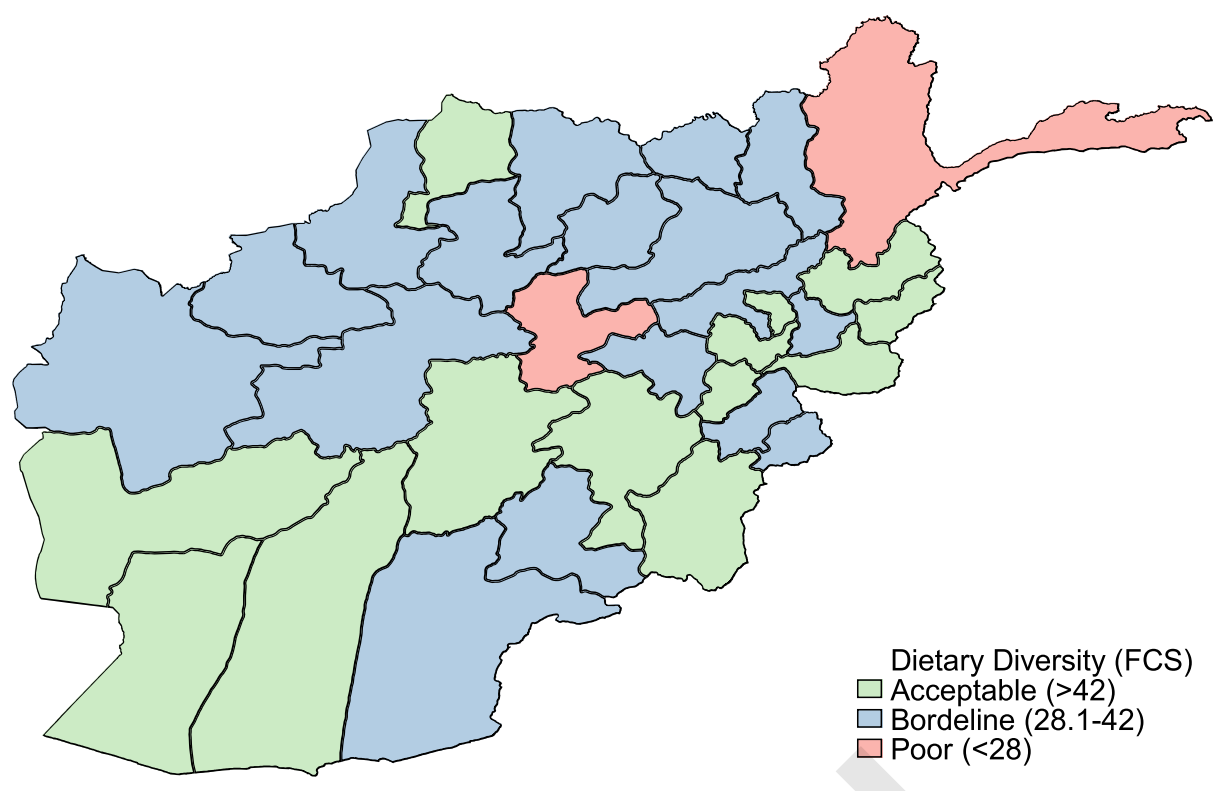

Map 1. Geographical distribution of dietary diversity (FCS).

seasons, even if the overall quality of diet is not at an acceptable level for many households. Geographical distribution of FCS also varies across Afghanistan (Map 1). Highland provinces, particularly Bamyan and Badakhshan, characterised by rugged terrain and high mountains, tend to have a lower dietary diversity than more level areas, such as the southern provinces and provinces around Kabul.

Turning to agricultural production, we see from Table 1 that Afghan agriculture is characterised by low cropping diversity at the farm level. On average, only 1.36 crops are grown by households with some agricultural involvement, underlining the heavy focus on wheat cropping in the local agricultural economy. Table 2 also reveals the importance of livestock in this setting - the mean number of livestock species raised is almost 2. Livestock raising is common even in urban areas where households may engage in no, or very limited, cropping. Table 3 presents proportions of households engaging in specific farming enterprises. Almost $60 \%$ of households with any agricultural involvement grow cereals (mostly wheat), while pulse production is a minor activity engaged in by $<5 \%$ of sampled households. Fruits and vegetables cultivations are engaged in by $14 \%$ of households in each case. Again, Table 3 highlights the ubiquity and importance of livestock $90 \%$ of households in our sample engage in some livestock production, significantly more than are involved in wheat production. While one may expect a large proportion of such widespread livestock raising to be poultry based, that is not the case in Afghanistan - 78\% of households with any agricultural involvement own a milk producing animal cows, buffaloes, goats, or sheep.

Table 4 provides a more detailed understanding of food consumption and its sourcing. Practically all households consumed cereals in the recall period of the survey. Milk, meat, and fish was also widely consumed, with almost 70 per cent reporting consumption. Slightly smaller proportions of the sample managed to consume pulses (63 per cent), while only 58 and 41 percent of sample households reported vegetable and fruit consumption respectively in the previous seven days. The information on sourcing of foods underscores once again the critical importance of market provisioning relative to own consumption even in a setting characterised by aspects such as poor infrastructure, difficult terrain and conflict that are conducive to market failures. For example, the majority of households managed to include pulses in their diets, but this almost exclusively came from market purchase. That said, there clearly are also specific food categories where subsistence provisioning is important. Almost three times as many households reported procuring milk from their own animals rather than from the market, reflecting the perishability of milk and the lack of cold chain infrastructure. As noted before, almost $80 \%$ per cent of the households own at least a cow, buffalo, sheep, or goat.

Table 4 shows also how diets vary across the regular and lean seasons for urban and rural samples. Intakes of cereals, pulses, and meat and fish remains more or less constant in the Afghan diet throughout the year, though we do we observe a reduction in the proportion of households consuming vegetables, fruit, and to a lesser extent milk, in the lean season. Nevertheless, considering the relative harshness of winter and infrastructural limitations, the picture appears to be one of reasonable success in smoothing diets across seasons, both in rural and urban areas.

Taken together with the dietary diversity information, they suggest that Afghan households manage to attain moderately diverse diets despite relatively low agricultural production diversity.

Next, we turn to market access and market food availability aspects. As seen from Table 1, rural households tend to encounter higher transport costs to the nearest market than urban households. On average, urban households need to spend just over 4 ANF to transport $50 \mathrm{~kg}$ of wheat to the nearest market. The cost encountered by rural households is tenfold, highlighting the thinness of markets and high cost of trade. Map 2 graphs the geographical differences in transport costs, with more remote and mountainous areas experiencing higher costs.

Table 5 shows the availability of foods in markets across the regular and lean seasons. A reduction in availability in the lean season is apparent for many foods, in particular fresh fruit and vegetables and milk/ dairy. Interestingly however, dried food availability rises in the lean season to compensate for some of the decline - dried fruit and dried meat availability increase substantially in the lean season. Map 3 graphs market food availability at province level. There is substantial variation in food availability across the country. Less mountainous provinces and provinces near the capital Kabul tend to have a better availability of food in the markets. More remote provinces, in particular in mountainous areas of Central Afghanistan, witness a more constrained supply of diverse food.

\subsection{Regression results}

6.2.1. Dietary diversity, agricultural production diversity, and market transport costs

First, we present results in Table 6 from a set of models that are 


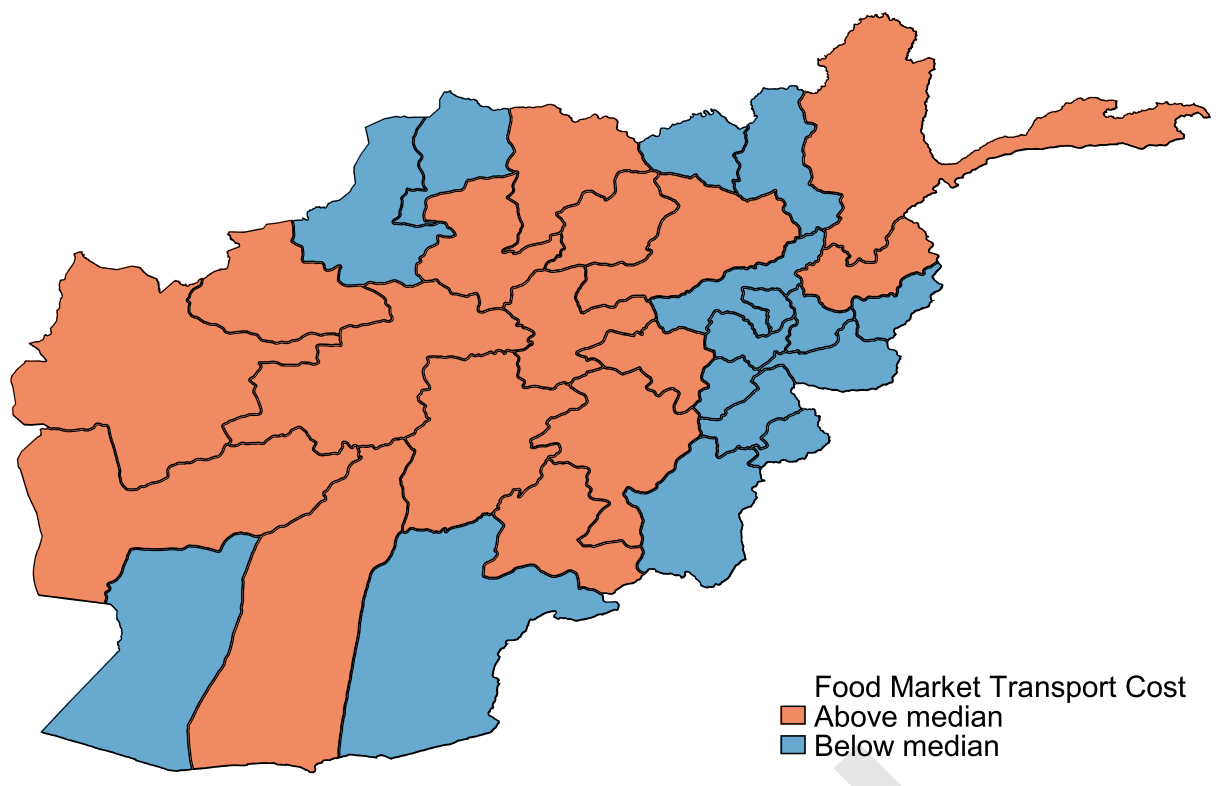

Map 2. Geographical distribution of market transportation costs.

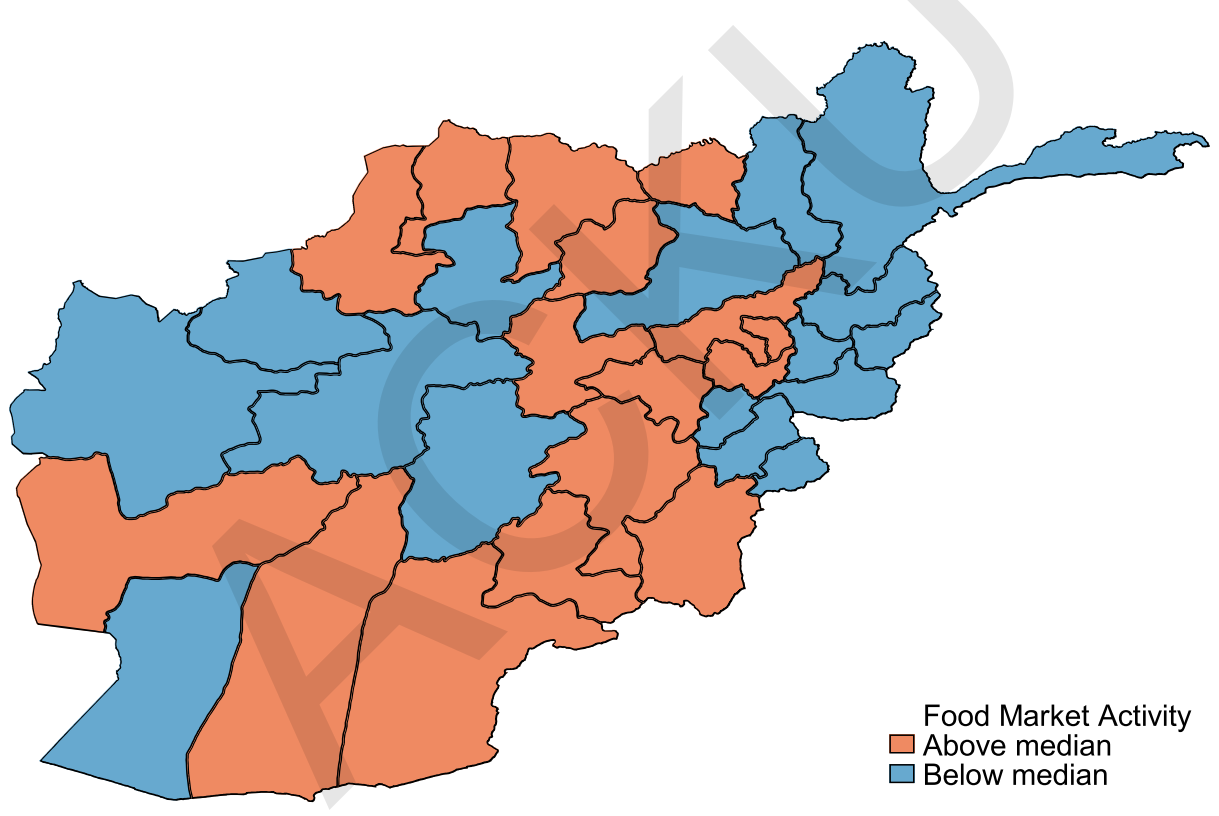

Map 3. Geographical distribution of market food availability.

parallel to the previous literature in this area but embed in the estimation the contribution of season. This is achieved interacting key variable of interest with a dummy variable that captures whether the household was surveyed during the lean season. For each model we present the OLS and IV specification. The most restrictive specification (Model I) includes only the (instrumented) crop and livestock diversity indices, and market transport costs. Progressively in subsequent columns we add to the estimation household characteristics (Model II), wealth quintiles (Model III), and province dummies (Model IV). Across the different models, we observe crop diversity being positively and significantly associated with FCS, although the estimated magnitude falls substantially when we add in the province dummies in Model IV. On the other hand, livestock diversity is seen to have little relationship with dietary diversity until the province dummies are added, whereupon a large and statistically significant positive relationship with dietary diversity is observed. The cost of transportation coefficient has a consistently negative sign across models, indicating that a higher cost of transportation (reflecting distance to markets and quality of infrastructure) is associated with less diverse diets. However, in the later models with a fuller set of controls, this association become statistically insignificant. The effect of lean season is constantly large in magnitude and significant across models. Model IV is our preferred model, controlling fully as it does for wealth and regional effects. ${ }^{8}$ The model indicates that production diversity is important, but that diversity in the raising of livestock species is particularly important for dietary diversity amongst rural Afghanis with an additive effect during the lean season. This nuance is not typically captured in models that use crop counts only or that aggregate crop and livestock counts.

Results between OLS and IV models are consistent in our preferred model, however OLS underestimates the role of crop diversity and do not capture the significant role of livestock diversity during the lean

\footnotetext{
${ }^{8}$ As a robustness check, we also estimated each of these models and the following ones using an aggregate production diversity index. Results are not significantly different (available on request).
} 
Table 6

Dietary diversity and production diversity.

\begin{tabular}{|c|c|c|c|c|c|c|c|c|}
\hline & \multicolumn{2}{|l|}{ I } & \multicolumn{2}{|l|}{ II } & \multicolumn{2}{|l|}{ III } & \multicolumn{2}{|l|}{ IV } \\
\hline & FCS (OLS) & FCS (IV) & FCS (OLS) & FCS (IV) & FCS (OLS) & FCS (IV) & FCS (OLS) & FCS (IV) \\
\hline \multirow[t]{2}{*}{ Crop Diversity Index (CDI) } & $1.178^{* * * *}$ & $2.346^{* * * k x}$ & $1.122^{k * *}$ & $2.757^{* * * *}$ & $1.044^{* * * *}$ & $2.877^{* * * *}$ & $0.862^{* * * *}$ & $1.852^{* * * *}$ \\
\hline & -0.218 & -0.748 & -0.22 & -0.826 & -0.215 & -0.836 & -0.165 & -0.69 \\
\hline \multirow[t]{2}{*}{ Crop Diversity Index $(\mathrm{CDI}) \times$ Lean season } & -0.019 & 0.178 & -0.246 & -0.457 & -0.179 & -0.369 & $-0.507^{*}$ & -1.307 \\
\hline & -0.421 & -1.331 & -0.403 & -1.302 & -0.38 & -1.245 & -0.307 & -0.894 \\
\hline \multirow[t]{2}{*}{ Livestock Diversity Index (LDI) } & $1.529^{k * * * k}$ & $-2.381^{* * * k}$ & $1.507^{* * * *}$ & -1.076 & $1.632^{* * * *}$ & -0.063 & $2.322^{* * * *}$ & 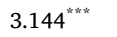 \\
\hline & -0.224 & -0.825 & -0.22 & -0.819 & -0.213 & -0.8 & -0.165 & -0.642 \\
\hline \multirow{2}{*}{ Livestock Diversity Index (LDI) $\times$ Lean season } & 0.355 & $3.187^{* *}$ & 0.257 & $2.587^{* *}$ & 0.219 & $2.148^{*}$ & 0.191 & $2.017^{\text {k** }}$ \\
\hline & -0.364 & -1.285 & -0.359 & -1.265 & -0.349 & -1.226 & -0.272 & -0.825 \\
\hline \multirow[t]{2}{*}{ MKT transport cost (log) } & $-0.666^{\text {tektik }}$ & $-0.467^{* *}$ & $-0.327^{*}$ & -0.217 & -0.129 & -0.074 & 0.038 & 0.013 \\
\hline & -0.186 & -0.191 & -0.181 & -0.182 & -0.177 & -0.177 & -0.113 & -0.118 \\
\hline \multirow[t]{2}{*}{ MKT transport cost $(\log ) \times$ Lean season } & -0.389 & $-0.575^{*}$ & -0.397 & $-0.531^{*}$ & -0.398 & $-0.511^{*}$ & -0.027 & -0.109 \\
\hline & -0.318 & -0.319 & -0.307 & -0.305 & -0.297 & -0.295 & -0.231 & -0.229 \\
\hline \multirow[t]{2}{*}{ Lean season } & $-2.176^{\star * *}$ & $-7.735^{* * * *}$ & -1.286 & $-5.542^{\text {*k }}$ & -1.183 & $-4.741^{\text {** }}$ & -1.262 & $-3.811^{\text {** }}$ \\
\hline & -1.024 & -2.299 & -1.003 & -2.245 & -0.978 & -2.171 & -0.769 & -1.649 \\
\hline Household characteristics ${ }^{\dagger}$ & $\mathrm{N}$ & $\mathrm{N}$ & $\mathrm{Y}$ & $\mathrm{Y}$ & $\mathrm{Y}$ & $\mathrm{Y}$ & $\mathrm{Y}$ & $\mathrm{Y}$ \\
\hline Wealth quintiles (5) & $\mathrm{N}$ & $\mathrm{N}$ & $\mathrm{N}$ & $\mathrm{N}$ & $\mathrm{Y}$ & $\mathrm{Y}$ & $\mathrm{Y}$ & $\mathrm{Y}$ \\
\hline Provinces (34) & $\mathrm{N}$ & $\mathrm{N}$ & $\mathrm{N}$ & $\mathrm{N}$ & $\mathrm{N}$ & $\mathrm{N}$ & $\mathrm{Y}$ & $\mathrm{Y}$ \\
\hline Durbin-Wu-Hausman test & & $10.23^{* * * k}$ & & $4.89^{* k * k}$ & & $3.88^{* * * *}$ & & $5.05^{\text {**k:k}}$ \\
\hline F-Test on sig. of instrument (CDI) & & $1056.33^{* * * *}$ & & $549.34^{\text {******}}$ & & $553.89^{* * * * k}$ & & $197.82^{* * * *}$ \\
\hline F-Test on sig. of instrument $(\mathrm{CDI} \times$ lean $)$ & & . & & $430.22^{* * * * *}$ & & $428.13^{\text {*t*k* }}$ & & $415.99^{* * * k}$ \\
\hline F-Test on sig. of instrument (LDI) & & $1023.65^{* * *}$ & & $675.09^{* * * *}$ & & $672.37^{* * * * *}$ & & $262.62^{* * * *}$ \\
\hline F-Test on sig. of instrument (LDI $\times$ lean) & & . & & $404.31^{\text {k.k*k }}$ & & $397.78^{\text {k*k }}$ & & $404.52^{\text {***k }}$ \\
\hline Wald chi2 & $31.63^{* * *}$ & $58.20^{* * *}$ & $38.66^{* * * *}$ & $502.56^{* * * *}$ & $38.57^{* * * *}$ & $638.74^{\text {****k }}$ & $100.06^{* * * *}$ & $4454.28^{\text {k***k}}$ \\
\hline Adjusted R-square & 0.04 & & 0.09 & 0.06 & 0.12 & 0.1 & 0.36 & 0.34 \\
\hline Observations & 14,079 & 14,079 & 14,079 & 14,079 & 14,079 & 14,079 & 14,079 & 14,079 \\
\hline
\end{tabular}

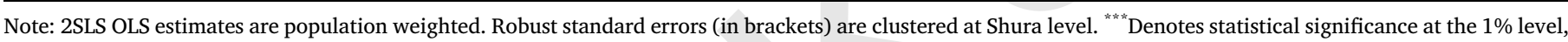

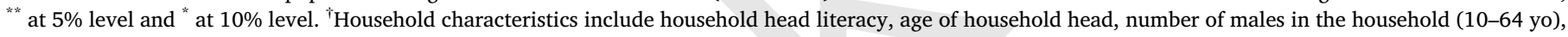

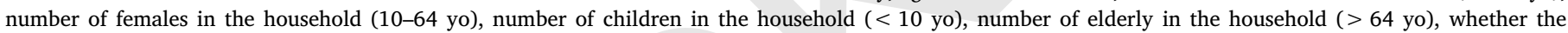

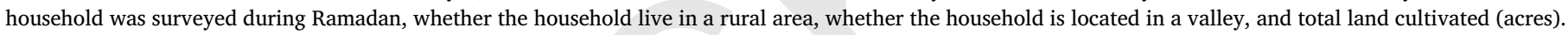
The full specifications are reported in Tables B and C (Appendix).

season. For each IV specification, we tested whether the crop and livestock diversity indices were exogenous (Durbin-Wu-Hausman test), checked that the instruments chosen (crop and livestock diversity index of the neighbours in the Shura) were not weak (5\% distortion from Wald test based on Stock and Yogo significance levels), and jointly estimated the model and the instrumental regression based on maximum likelihood. In our preferred specification (Model IV) we reject the hypothesis of exogeneity of the agricultural production indexes ( $\rho=[0.00-0.00])$ and the chosen instruments are found to be adequately strong $(F=[197.82-415.99], \quad \rho=0.00, \quad R-$ squared $=[0.26-0.75]$, Stock and Yogo $=16.38)$.

\subsubsection{Beyond market access: Food availability in markets}

Table 7 demonstrates the important seasonal dimension to the way in which production diversity and market access/infrastructure impact dietary diversity. The model I repeats results from the previous subsection, indicating that crop diversity as well as livestock diversity are positively associated with dietary diversity but that the market transport costs variable is not statistically significant. Crop diversity is seen to be particularly important for dietary diversity in the regular season. Livestock diversity is positively associated with dietary diversity year around, but particularly so in the lean season. Market transport cost does not have a statistically significant relationship with dietary diversity, either in the regular or lean season.

In model II we introduce the Market Food Availability Index (MFAI), an indicator of the typical availability of a set of key foods in the market at the time of the survey interview. The results of the main variables of interest, i.e. production diversity and market transportation costs, are not different to the estimations of model I, either qualitatively or in terms of magnitude. However, the results show that variables relating to market access/infrastructure, e.g. distance to the market or cost of transport, capture only part of the role of market on dietary diversity. Increased availability of foods is positively and significantly associated with dietary diversity, significantly only during the lean season. This effect is captured both in the OLS and IV models. As with market transportation costs, the variety of foods available in the market is comparatively unimportant in the regular season when provisioning from own production is more viable. However, market food availability becomes particularly important in the lean season.

\section{Discussion and conclusions}

Improved dietary quality and variety are central to the nutrition, well-being and life prospects of the majority of the poorest in the world. The agriculture sector has a prominent role to play in alleviating malnutrition. Smallholders are an important constituency in this effort, given their disproportionate vulnerability to undernutrition and hunger, as well as their role as providers of food (Wiggins and Keats, 2013). As the academic as well as practitioner and policy communities gear up to meet the challenge of making agriculture more nutritionsensitive, much of the debate and many of the emerging solutions relate to improving the dietary diversity of smallholders via improved diversity in agricultural production at the farm level. Some scholars have noted that the role of markets in enabling the nutrition, both of smallholders as well as the wider population, must not be neglected in the process of emphasising improved production diversity. Thus, smallholder access to markets has been shown to have at least as important a role in improving smallholder diets as increased on-farm production diversity.

Agriculture, markets as well as diets have the potential to be highly seasonal in many developing countries. How food markets and production diversity might interact across seasons to influence smallholder 
Table 7

Dietary diversity, production diversity and Market Food Availability.

\begin{tabular}{|c|c|c|c|c|}
\hline & \multicolumn{2}{|l|}{ I } & \multicolumn{2}{|l|}{ II } \\
\hline & FCS (OLS) & FCS (IV) & FCS (OLS) & FCS (IV) \\
\hline Crop Diversity Index (CDI) & $\begin{array}{l}0.862^{* * * *} \\
(0.165)\end{array}$ & $\begin{array}{l}1.852^{\text {v*k*k }} \\
(0.690)\end{array}$ & $\begin{array}{l}0.847^{* * * * *} \\
(0.165)\end{array}$ & $\begin{array}{l}1.749^{* * *} \\
(0.693)\end{array}$ \\
\hline $\begin{array}{l}\text { Crop Diversity Index } \\
\quad(\mathrm{CDI}) \times \text { Lean season }\end{array}$ & $\begin{array}{l}-0.507^{*} \\
(0.307)\end{array}$ & $\begin{array}{l}-1.307 \\
(0.894)\end{array}$ & $\begin{array}{l}-0.525^{*} \\
(0.302)\end{array}$ & $\begin{array}{l}-1.405 \\
(0.883)\end{array}$ \\
\hline $\begin{array}{l}\text { Livestock Diversity Index } \\
\text { (LDI) }\end{array}$ & $\begin{array}{l}2.322^{* k \times *} \\
(0.165)\end{array}$ & $\begin{array}{l}3.144^{\text {xkex }} \\
(0.642)\end{array}$ & $\begin{array}{l}2.319^{* * x * x} \\
(0.165)\end{array}$ & $\begin{array}{l}3.110^{* k * k} \\
(0.656)\end{array}$ \\
\hline $\begin{array}{l}\text { Livestock Diversity Index } \\
(\text { LDI }) \times \text { Lean season }\end{array}$ & $\begin{array}{l}0.191 \\
(0.272)\end{array}$ & $\begin{array}{l}2.017^{* * k} \\
(0.825)\end{array}$ & $\begin{array}{l}0.210 \\
(0.272)\end{array}$ & $\begin{array}{l}2.174^{\text {knkik }} \\
(0.835)\end{array}$ \\
\hline $\begin{array}{l}\text { Market Food Availability } \\
\text { Index (MFAI) }\end{array}$ & & & $\begin{array}{l}0.861 \\
(0.766)\end{array}$ & $\begin{array}{l}0.963 \\
(0.785)\end{array}$ \\
\hline $\begin{array}{l}\text { Market Food Availability } \\
\text { Index }(\text { MFAI) } \times \text { Lean } \\
\text { season }\end{array}$ & & & $3.431^{\text {xkk:k }}$ & $3.347^{\text {*k*k}}$ \\
\hline MKT transport cost (log) & $\begin{array}{l}0.038 \\
(0.113)\end{array}$ & $\begin{array}{l}0.013 \\
(0.118)\end{array}$ & $\begin{array}{l}(1.090) \\
0.028 \\
(0.111)\end{array}$ & $\begin{array}{l}(1.083) \\
0.007 \\
(0.116)\end{array}$ \\
\hline $\begin{array}{l}\text { MKT transport cost } \\
\quad(\log ) \times \text { Lean season }\end{array}$ & $\begin{array}{l}-0.027 \\
(0.231)\end{array}$ & $\begin{array}{l}-0.109 \\
(0.229)\end{array}$ & $\begin{array}{l}0.040 \\
(0.231)\end{array}$ & $\begin{array}{l}-0.049 \\
(0.229)\end{array}$ \\
\hline Lean season & $\begin{array}{l}-1.262 \\
(0.769)\end{array}$ & $\begin{array}{l}-3.811^{\text {k* }} \\
(1.649)\end{array}$ & $\begin{array}{l}-4.050^{\text {k*k*k}} \\
(1.219)\end{array}$ & $\begin{array}{l}-6.667^{* * * k} \\
(1.908)\end{array}$ \\
\hline Household characteristics ${ }^{\dagger}$ & $\mathrm{Y}$ & $\mathrm{Y}$ & $\mathrm{Y}$ & $\mathrm{Y}$ \\
\hline Wealth quintiles (5) & $\mathrm{Y}$ & $\mathrm{Y}$ & $\mathrm{Y}$ & $\mathrm{Y}$ \\
\hline Provinces (34) & $\mathrm{Y}$ & $\mathrm{Y}$ & $\mathrm{Y}$ & $\mathrm{Y}$ \\
\hline Durbin-Wu-Hausman test & & $5.05^{* \ldots * k}$ & & $5.14^{\text {k*k*k}}$ \\
\hline $\begin{array}{l}\text { F-Test on sig. of instrument } \\
\text { (CDI) }\end{array}$ & & $197.82^{* * * * *}$ & & $196.48^{\text {*k*k }}$ \\
\hline $\begin{array}{l}\text { F-Test on sig. of instrument } \\
(\mathrm{CDI} \times \text { lean })\end{array}$ & & $415.99^{* * * * x}$ & & $417.80^{* * * * k}$ \\
\hline $\begin{array}{l}\text { F-Test on sig. of instrument } \\
\text { (LDI) }\end{array}$ & & $262.62^{\text {*k*kek }}$ & & $258.08^{* * \ldots k k}$ \\
\hline $\begin{array}{l}\text { F-Test on sig. of instrument } \\
\quad(\text { LDI } \times \text { lean })\end{array}$ & & $404.52^{* * * k t}$ & & $405.98^{\text {***k }}$ \\
\hline Wald chi2 & $100.06^{* * * *}$ & $4454.28^{* * * * *}$ & $96.52^{k * * *}$ & $4502.96^{* * * * *}$ \\
\hline Adjusted R-square & 0.36 & 0.34 & 0.36 & 0.34 \\
\hline Observations & 14,079 & 14,079 & 14,079 & 14,079 \\
\hline
\end{tabular}

Note: 2SLS OLS estimates are population weighted. Robust standard errors (in brackets) are clustered at Shura level. ${ }^{* * *}$ Denotes statistical significance at the $1 \%$ level, ${ }^{* *}$ at $5 \%$ level and * at $10 \%$ level. 'Household characteristics include household head literacy, age of household head, number of males in the household (10-64 years old), number of females in the household (10-64 years old), number of children in the household ( $<10$ years old), number of elderly in the household ( $>64$ years old), whether the household was surveyed during Ramadan, whether the household live in a rural area, whether the household is located in a valley, and total land cultivated (acres). The full specifications are reported in Table D (Appendix).

diets is not well understood hitherto. Furthermore, the market dimension encompasses more than access - the diversity of foods available in local markets is plausibly as important as production diversity in determining smallholder diets, although this has not been investigated. This study has attempted to fill these lacunae. Our Afghan setting, with its smallholder-dominated agricultural production, strongly seasonal agricultural calendar and terrain and conditions conducive to market failures, is particularly suitable for examining the questions we have posed.

We found that over $50 \%$ of Afghan diets in the 2013-14 season were 'borderline' or 'poor' according to WFP classifications. However, dietary diversity was observed to be remarkably stable between the regular and lean seasons, even if there was a dip in the consumption of certain categories such as fruits and vegetables during the winter lean period.
Another striking observation from the data was that the bulk of dietary diversity in Afghanistan, about 60\%, derives from markets. Cropping diversity is very limited, but livestock raising is ubiquitous. Analysis of availability of foods in local markets revealed an interesting pattern offering a clue regarding one aspect of how markets may help deliver dietary diversity in the lean season: when the market availability of fresh fruit, vegetables and meat diminishes over the harsh winter, availability of dried fruit and meat surges to partially compensate. Our regression results reveal that production diversity is important in general, but that diversity in the raising of livestock species is particularly important for dietary diversity amongst Afghan agricultural producers. We confirm an important seasonal dimension to the way in which production diversity and market access/infrastructure impact dietary diversity. Improved crop diversity is positively associated with dietary diversity in the regular season, but not so in the lean season, when cropping possibilities and stored food from own production in the regular season dwindle. On the other hand, livestock species diversity remains important for dietary diversity throughout the year, but particularly so in the lean season when cropping diversity becomes less relevant. A key pathway from livestock diversity to dietary diversity in the lean season in the Afghanistan context arises from additional diversity in livestock holdings providing more avenues for income from sale of livestock or livestock products. In contrast to the limited storage potential of crop outputs, the keeping of live animals for revenue generation finances market purchase of crop as well as livestock foods in the lean season. In particular, the sale of chicken eggs and meat from sheep is noteworthy (Flores-Martinez et al., 2016). Additionally, greater diversity in livestock keeping also helps maintain dietary diversity in the lean season from consumption from own-production. Cattle and goats are kept predominantly for milk production (Central Statistics Organisation, 2016) and are particularly important for maintaining dairy intakes in the lean season when market availability of milk declines markedly (Table 4). Market transport costs are found to not have a significant relationship with dietary diversity in the regular season when consumption possibilities from own production are plentiful. However, in the lean season, as consumption from own production becomes more challenging, lower transport costs to the market do have a positive relationship with dietary diversity. Finally, our hypothesis that the diversity of foods available in the market is positively related to dietary diversity is confirmed. As with market transport costs, market food availability becomes particularly important to diet in the lean season. These findings have important implications for policy, practice as well as future research. Firstly, our results suggest that local strategies to improve dietary diversity via agriculture can benefit from taking a season-specific approach. In Afghanistan, investments in livestock enterprises and improving market infrastructure are particularly likely to benefit diets in the lean season, when households may struggle the most to obtain a diverse diet. With regard to market sourcing of dietary diversity, much of the attention in the literature as well as practice is currently focused on 'value chains for nutrition', which tends to focus on individual food products. While such attention has delivered important insights, results from this study as well as other literature in this area, indicate the need to also focus on broad-based investments in providing market infrastructure - lowering transport costs and improving market access at the local level - these actions cut across food products and are potentially offer a cost-effective means to improving dietary diversity across seasons. A second implication relates to the importance of the diversity of foods available in the market, shown in this study to have an important bearing on dietary diversity. Again, market-related infrastructure will be important to this - not just at the local level to connect farmers to markets, but at the inter-regional level to improve market integration and enable food products to flow from the rest of Afghanistan as well as neighbouring countries. Investments in simple and cheap drying and storage technologies are also likely to help, as exemplified in the Afghanistan case by the market availability of dried fruit and meats in the lean season. Finally, we fully 
acknowledge the shortcomings of the research reported here. Not all our information is available within a single dataset, and we have had to match and merge information across datasets to enable analysis of a specific feature of special interest to this paper, market food availability. Secondly, the validity of our instrumental variables strategy is debatable, and causal interpretations need to be made cautiously. Despite these shortcomings, this research enables insight into the seasonal interplay between production diversity, food markets and dietary diversity in a rarely investigated setting such as Afghanistan.

\section{Acknowledgements}

This article is part of the research generated by the Leveraging Agriculture for Nutrition in South Asia Research (LANSA) research consortium and is funded by UK aid from the UK Government. The views expressed do not necessarily reflect the UK Government's official policies. We are grateful for comments by participants at the ANH Conference in Addis Ababa, 2016 and the IAAE Silk Road Conference in Almaty, 2016. We thank the Central Statistics Organization, Government of Afghanistan, for access to the ALCS and NRVA datasets.

\section{Appendix A}

See Tables A-D.

Table A

Lean season by Province.

Source: CSO, 2014.

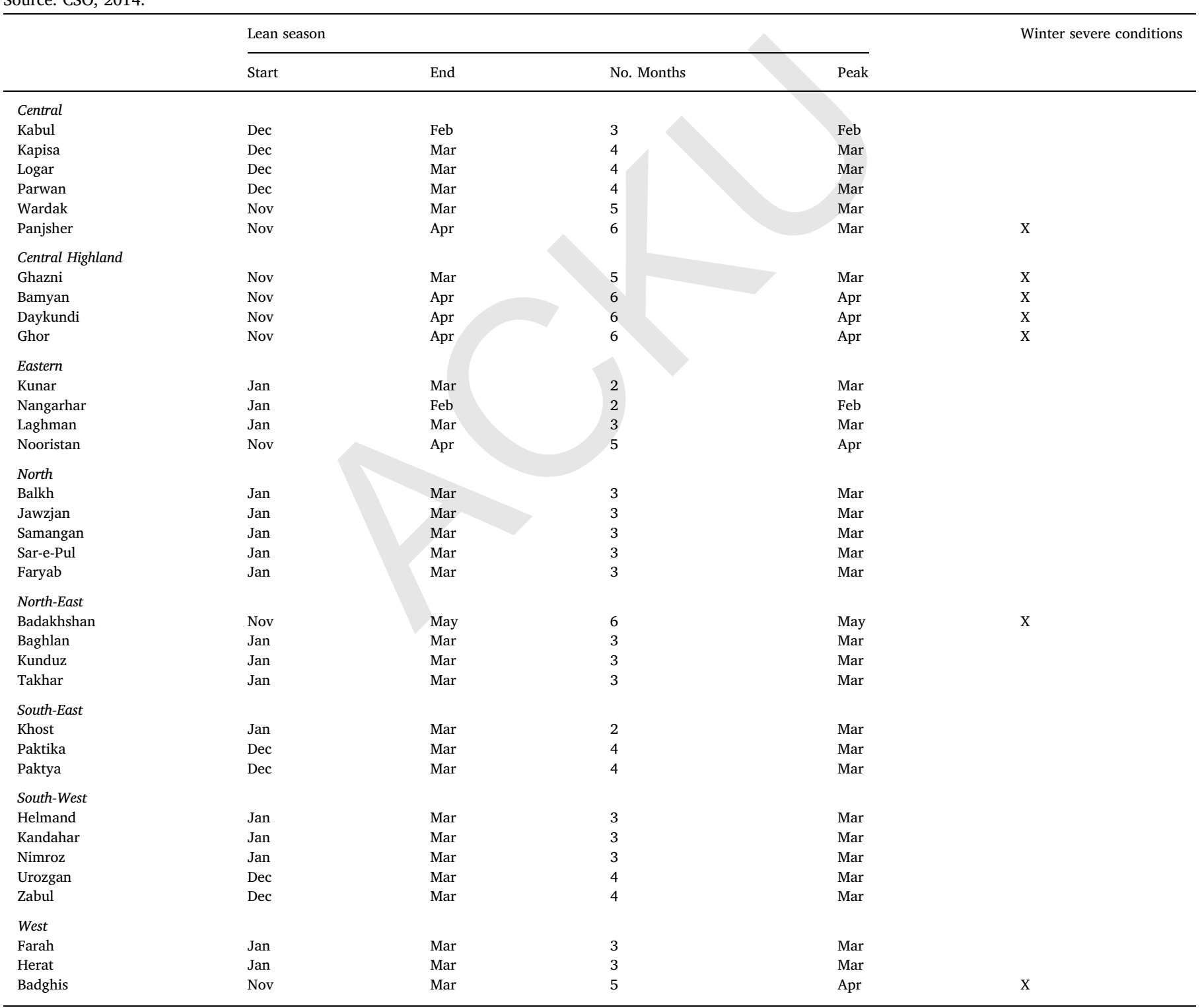


Table B

Dietary diversity and production diversity (full results, OLS).

\begin{tabular}{|c|c|c|c|c|}
\hline & (I) & (II) & (III) & (IV) \\
\hline \multirow[t]{2}{*}{ Crop Diversity Index (CDI) } & $1.178^{* * * *}$ & $1.122^{* * * x}$ & $1.044^{* * * *}$ & $0.862^{* * * k}$ \\
\hline & $(0.218)$ & $(0.220)$ & $(0.215)$ & $(0.165)$ \\
\hline \multirow{2}{*}{$\begin{array}{l}\text { Crop Diversity Index } \\
\quad(\mathrm{CDI}) \times \text { Lean season }\end{array}$} & -0.019 & -0.246 & -0.179 & $-0.507^{*}$ \\
\hline & $(0.421)$ & $(0.403)$ & $(0.380)$ & $(0.307)$ \\
\hline \multirow[t]{2}{*}{ Livestock Diversity Index (LDI) } & $1.529^{* * * k * k}$ & $1.507^{* * * * *}$ & $1.632^{* * * * *}$ & $2.322^{* * * k *}$ \\
\hline & $(0.224)$ & $(0.220)$ & $(0.213)$ & $(0.165)$ \\
\hline \multirow{2}{*}{$\begin{array}{l}\text { Livestock Diversity Index } \\
\text { (LDI) } \times \text { Lean season }\end{array}$} & 0.355 & 0.257 & 0.219 & 0.191 \\
\hline & $(0.364)$ & $(0.359)$ & $(0.349)$ & (0. 272) \\
\hline \multirow[t]{2}{*}{ MKT transport cost (log) } & $-0.666^{\text {***k }}$ & $-0.327^{*}$ & -0.129 & 0.038 \\
\hline & $(0.186)$ & $(0.181)$ & $(0.177)$ & $(0.113)$ \\
\hline \multirow{2}{*}{$\begin{array}{l}\text { MKT transport cost } \\
\quad(\log ) \times \text { Lean season }\end{array}$} & -0.389 & -0.397 & -0.398 & -0.027 \\
\hline & $(0.318)$ & $(0.307)$ & $(0.297)$ & $(0.231)$ \\
\hline \multirow[t]{2}{*}{ Lean season } & $-2.176^{\text {k*k }}$ & -1.286 & -1.183 & -1.262 \\
\hline & $(1.024)$ & $(1.003)$ & $(0.978)$ & $(0.769)$ \\
\hline \multirow{2}{*}{ Urban } & & $2.644^{\text {*****}}$ & -0.639 & 0.106 \\
\hline & & $(0.924)$ & $(0.917)$ & $(0.830)$ \\
\hline \multirow[t]{2}{*}{ Household head literate } & & $4.457^{* * * *}$ & $3.146^{\text {k*k*k}}$ & $2.118^{* * * k}$ \\
\hline & & $(0.411)$ & $(0.388)$ & $(0.312)$ \\
\hline \multirow[t]{2}{*}{ Age of household head } & & 0.009 & 0.016 & $0.021^{*}$ \\
\hline & & $(0.014)$ & $(0.013)$ & $(0.011)$ \\
\hline \multirow[t]{2}{*}{ Number of females (10-64 yo) } & & $0.678^{* \ldots * x}$ & $0.379^{* * * *}$ & $0.310^{* * * k}$ \\
\hline & & $(0.149)$ & $(0.140)$ & $(0.117)$ \\
\hline \multirow[t]{2}{*}{ Number of males (10-64 yo) } & & $1.166^{\text {***** }}$ & $0.894^{* * * *}$ & $0.523^{* * * k}$ \\
\hline & & $(0.126)$ & $(0.125)$ & $(0.102)$ \\
\hline \multirow[t]{2}{*}{ Number of children (< 10 yo) } & & $0.255^{* * * * x}$ & $0.294^{\text {k*k***1}}$ & 0.093 \\
\hline & & $(0.082)$ & $(0.081)$ & $(0.063)$ \\
\hline \multirow[t]{2}{*}{ Number of elderly ( $>64$ yo) } & & -0.142 & -0.506 & -0.193 \\
\hline & & $(0.358)$ & $(0.347)$ & $(0.288)$ \\
\hline \multirow[t]{2}{*}{ Ramadan } & & $3.891^{* * * *}$ & $3.943^{* * * *}$ & $3.529^{* * * *}$ \\
\hline & & $(1.330)$ & $(1.296)$ & $(0.692)$ \\
\hline \multirow[t]{2}{*}{ Located in a valley } & & $-2.824^{* * * *}$ & $-2.635^{* \ldots \ldots k}$ & 0.146 \\
\hline & & $(0.915)$ & $(0.904)$ & $(0.597)$ \\
\hline \multirow[t]{2}{*}{ Total land cultivated (acres) } & & -0.004 & -0.006 & $0.018^{*}$ \\
\hline & & $(0.012)$ & $(0.012)$ & $(0.011)$ \\
\hline \multirow[t]{2}{*}{ Wealth Index (II quintile) } & & & $1.795^{* * * * k}$ & $0.798^{*}$ \\
\hline & & & $(0.528)$ & $(0.427)$ \\
\hline \multirow[t]{2}{*}{ Wealth Index (III quintile) } & & & $2.948^{* * * *}$ & $1.932^{* * *}$ \\
\hline & & & $(0.583)$ & $(0.460)$ \\
\hline \multirow[t]{2}{*}{ Wealth Index (IV quintile) } & & & $5.154^{* x+\ldots x}$ & $2.919^{* * * *}$ \\
\hline & & & $(0.704)$ & $(0.480)$ \\
\hline \multirow[t]{2}{*}{ Wealth Index (V quintile) } & & & $9.394^{\text {k*k*k }}$ & $6.713^{* * * k}$ \\
\hline & & & $(0.817)$ & $(0.629)$ \\
\hline Provinces (34) & $\mathrm{Y}$ & $\mathrm{Y}$ & $\mathrm{Y}$ & $\mathrm{Y}$ \\
\hline Wald chi2 & $31.63^{\text {*n*ktk }}$ & $38.66^{\text {****kx}}$ & $38.57^{\text {k*k** }}$ & $100.06^{\text {**n*k*x}}$ \\
\hline R-square & 0.04 & 0.09 & 0.12 & 0.36 \\
\hline Adjusted R-square & 0.04 & 0.09 & 0.12 & 0.36 \\
\hline Observations & 14,079 & 14,079 & 14,079 & 14,079 \\
\hline
\end{tabular}

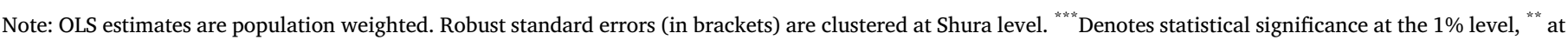
$5 \%$ level and * at $10 \%$ level. 
Table C

Dietary diversity and production diversity (full results, 2SLS OLS).

\begin{tabular}{|c|c|c|c|c|}
\hline & (I) & (II) & (III) & (IV) \\
\hline \multirow[t]{2}{*}{ Crop Diversity Index (CDI) } & $2.346^{\text {****}}$ & $2.757^{* * * k}$ & $2.877^{\text {***k }}$ & $1.852^{\text {****}}$ \\
\hline & $(0.748)$ & $(0.826)$ & $(0.836)$ & $(0.690)$ \\
\hline \multirow{2}{*}{$\begin{array}{l}\text { Crop Diversity Index } \\
\qquad(\mathrm{CDI}) \times \text { Lean season }\end{array}$} & 0.178 & -0.457 & -0.369 & -1.307 \\
\hline & $(1.331)$ & $(1.302)$ & $(1.245)$ & $(0.894)$ \\
\hline \multirow{2}{*}{$\begin{array}{l}\text { Livestock Diversity Index } \\
\quad \text { (LDI) }\end{array}$} & $-2.381^{\text {**** }}$ & -1.076 & -0.063 & $3.144^{* * * * * *}$ \\
\hline & $(0.825)$ & $(0.819)$ & $(0.800)$ & $(0.642)$ \\
\hline \multirow{2}{*}{$\begin{array}{l}\text { Livestock Diversity Index } \\
\quad(\text { LDI }) \times \text { Lean season }\end{array}$} & $3.187^{* * *}$ & $2.587^{\text {**k }}$ & $2.148^{*}$ & $2.017^{* * *}$ \\
\hline & $(1.285)$ & $(1.265)$ & $(1.226)$ & $(0.825)$ \\
\hline \multirow[t]{2}{*}{ MKT transport cost (log) } & $-0.467^{* *}$ & -0.217 & -0.074 & 0.013 \\
\hline & $(0.191)$ & $(0.182)$ & $(0.177)$ & $(0.118)$ \\
\hline \multirow{2}{*}{$\begin{array}{l}\text { MKT transport cost } \\
\quad(\log ) \times \text { Lean season }\end{array}$} & $-0.575^{*}$ & $-0.531^{*}$ & $-0.511^{*}$ & -0.109 \\
\hline & $(0.319)$ & $(0.305)$ & $(0.295)$ & $(0.229)$ \\
\hline \multirow[t]{2}{*}{ Lean season } & $-7.735^{* \ldots * k}$ & $-5.542^{\text {**k }}$ & $-4.741^{* * *}$ & $-3.811^{* *}$ \\
\hline & $(2.299)$ & $(2.245)$ & $(2.171)$ & $(1.649)$ \\
\hline \multirow{2}{*}{ Urban } & & $2.953^{k \times k *}$ & 0.498 & 1.272 \\
\hline & & $(1.128)$ & (1.109) & $(0.946)$ \\
\hline \multirow[t]{2}{*}{ Household head literate } & & $4.233^{* k \times k}$ & $2.967^{* * \ldots k}$ & $2.219^{k * * * x}$ \\
\hline & & $(0.407)$ & $(0.392)$ & $(0.317)$ \\
\hline \multirow[t]{2}{*}{ Age of household head } & & 0.014 & 0.017 & 0.013 \\
\hline & & $(0.014)$ & $(0.013)$ & $(0.011)$ \\
\hline \multirow{2}{*}{$\begin{array}{l}\text { Number of females (10-64 } \\
\text { yo) }\end{array}$} & & $0.713^{* * * *}$ & $0.386^{* * *}$ & $0.201^{*}$ \\
\hline & & $(0.150)$ & $(0.142)$ & $(0.121)$ \\
\hline \multirow[t]{2}{*}{ Number of males (10-64 yo) } & & $1.127^{* k * k}$ & $0.812^{* * * k}$ & $0.367^{\text {****}}$ \\
\hline & & $(0.137)$ & $(0.136)$ & $(0.115)$ \\
\hline \multirow{2}{*}{$\begin{array}{l}\text { Number of children }(<10 \\
\text { yo) }\end{array}$} & & $0.318^{* k * k}$ & $0.323^{\text {w*k*k }}$ & 0.047 \\
\hline & & $(0084)$ & $(0 \cap 02)$ & $(0,064)$ \\
\hline \multirow[t]{2}{*}{ Number of elderly ( $>64$ yo) } & & $\begin{array}{l}(0.084) \\
-0.249\end{array}$ & $-0.595^{*}$ & $\begin{array}{l}(0.064) \\
-0.322\end{array}$ \\
\hline & & $(0.359)$ & $(0.347)$ & $(0.295)$ \\
\hline \multirow[t]{2}{*}{ Ramadan } & & $3.525^{\text {k*kik }}$ & $3.608^{\text {k*kik }}$ & $3.535^{\text {*****}}$ \\
\hline & & $(1.297)$ & $(1.272)$ & $(0.698)$ \\
\hline \multirow[t]{2}{*}{ Located in a valley } & & $-2.600^{* * * *}$ & $-2.655^{* \text { **ke }}$ & -0.084 \\
\hline & & $(0.924)$ & $(0.919)$ & $(0.603)$ \\
\hline \multirow[t]{2}{*}{ Total land cultivated (acres) } & & -0.022 & $-0.035^{*}$ & -0.012 \\
\hline & & $(0.019)$ & $(0.019)$ & $(0.016)$ \\
\hline \multirow[t]{2}{*}{ Wealth Index (II quintile) } & & & $1.762^{\text {wiktk }}$ & 0.545 \\
\hline & & & $(0.534)$ & $(0.438)$ \\
\hline \multirow[t]{2}{*}{ Wealth Index (III quintile) } & & & $2.640^{* * * * k}$ & $1.588^{* * * *}$ \\
\hline & & & $(0.585)$ & $(0.478)$ \\
\hline \multirow[t]{2}{*}{ Wealth Index (IV quintile) } & & & $4.865^{* * * k}$ & $2.709^{* \ldots * k}$ \\
\hline & & & $(0.681)$ & $(0.498)$ \\
\hline \multirow[t]{2}{*}{ Wealth Index (V quintile) } & & & $9.072^{* * * k}$ & $6.485^{\text {*****}}$ \\
\hline & & & $(0.803)$ & $(0.645)$ \\
\hline Provinces (34) & $\mathrm{Y}$ & $\mathrm{Y}$ & $\mathrm{Y}$ & $\mathrm{Y}$ \\
\hline Durbin-Wu-Hausman test & $10.23^{\text {***kth}}$ & $4.89^{\text {k*k*k }}$ & $3.88^{\text {k*k*k}}$ & $5.05^{\text {*k*k }}$ \\
\hline $\begin{array}{l}\text { F-Test on sig. of instrument } \\
\text { (CDI) }\end{array}$ & $1056.33^{\text {**k*kx}}$ & $549.34^{* * * * *}$ & $553.89^{* * * * *}$ & $197.82^{* * * *}$ \\
\hline $\begin{array}{l}\text { F-Test on sig. of instrument } \\
\quad(\mathrm{CDI} \times \text { lean })\end{array}$ & . & $430.22^{* * * k}$ & $428.13^{* * * *}$ & $415.99^{* * * *}$ \\
\hline $\begin{array}{l}\text { F-Test on sig. of instrument } \\
\text { (LDI) }\end{array}$ & $1023.65^{* * *}$ & $675.09^{* * * *}$ & $672.37^{* * * *}$ & $262.62^{* * * k}$ \\
\hline $\begin{array}{l}\text { F-Test on sig. of instrument } \\
\quad(\text { LDI } \times \text { lean })\end{array}$ & . & $404.31^{\text {**** }}$ & $397.78^{* * * x}$ & $404.52^{\text {k*kik }}$ \\
\hline Wald chi2 & $58.20^{* * * * *}$ & $502.56^{* * * * * x}$ & $638.74^{\text {*k*kx}}$ & $4454.28^{\text {k*knke }}$ \\
\hline Adjusted R-square & . & 0.06 & 0.10 & 0.34 \\
\hline Observations & 14,079 & 14,079 & 14,079 & 14,079 \\
\hline
\end{tabular}

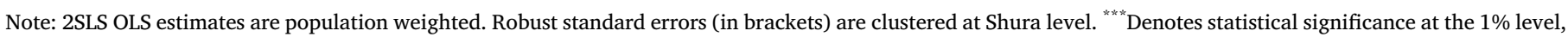
** at $5 \%$ level and * at $10 \%$ level. 
Table D

Dietary diversity and production diversity: The role of Food market availability (full results).

\begin{tabular}{|c|c|c|c|c|}
\hline & FCS (OLS) & FCS (IV) & FCS (OLS) & FCS (IV) \\
\hline \multirow[t]{2}{*}{ Crop Diversity Index (CDI) } & $0.862^{* * * k}$ & $1.852^{* * * *}$ & $0.847^{* * * k}$ & $1.749^{* * *}$ \\
\hline & $(0.165)$ & $(0.690)$ & $(0.165)$ & $(0.693)$ \\
\hline \multirow{2}{*}{$\begin{array}{l}\text { Crop Diversity Index } \\
\qquad(\mathrm{CDI}) \times \text { Lean season }\end{array}$} & $-0.507^{*}$ & -1.307 & $-0.525^{*}$ & -1.405 \\
\hline & $(0.307)$ & $(0.894)$ & $(0.302)$ & $(0.883)$ \\
\hline \multirow{2}{*}{$\begin{array}{l}\text { Livestock Diversity Index } \\
\text { (LDI) }\end{array}$} & $2.322^{\text {*n*k*k }}$ & $3.144^{k * * * *}$ & $2.319^{* x+k x}$ & $3.110^{* * * *}$ \\
\hline & $(0.165)$ & $(0.642)$ & $(0.165)$ & $(0.656)$ \\
\hline \multirow{2}{*}{$\begin{array}{l}\text { Livestock Diversity Index } \\
\quad(\text { LDI }) \times \text { Lean season }\end{array}$} & 0.191 & $2.017^{k * k}$ & 0.210 & $2.174^{k * * * x}$ \\
\hline & $(0.272)$ & $(0.825)$ & $(0.272)$ & $(0.835)$ \\
\hline \multirow{3}{*}{$\begin{array}{l}\text { Market Food Availability } \\
\text { Index (MFAI) }\end{array}$} & & & 0.861 & 0.963 \\
\hline & & & & \\
\hline & & & $(0.766)$ & $(0.785)$ \\
\hline \multirow{3}{*}{$\begin{array}{l}\text { Market Food Availability } \\
\text { Index }(\text { MFAI) } \times \text { Lean } \\
\text { season }\end{array}$} & & & $3.431^{* * * k}$ & $3.347^{* * * * k}$ \\
\hline & & & & \\
\hline & & & $(1.090)$ & $(1.083)$ \\
\hline \multirow{2}{*}{$\begin{array}{l}\text { MKT transport cost } \\
\quad(\log ) \times \text { Lean season }\end{array}$} & 0.038 & 0.013 & 0.028 & 0.007 \\
\hline & $(0.113)$ & $(0.118)$ & $(0.111)$ & $(0.116)$ \\
\hline \multirow[t]{2}{*}{ MKT transport cost (log) } & -0.027 & -0.109 & 0.040 & -0.049 \\
\hline & $(0.231)$ & $(0.229)$ & $(0.231)$ & $(0.229)$ \\
\hline \multirow{2}{*}{ Lean season } & -1.262 & $-3.811^{* *}$ & $-4.050^{* * \ldots}$ & $-6.667^{* * *}$ \\
\hline & $(0.769)$ & $(1.649)$ & $(1.219)$ & $(1.908)$ \\
\hline \multirow[t]{2}{*}{ Urban } & 0.106 & 1.272 & -0.002 & 1.076 \\
\hline & $(0.830)$ & $(0.946)$ & $(0.829)$ & $(0.942)$ \\
\hline \multirow[t]{2}{*}{ Household head literate } & $2.118^{\text {k*k*k}}$ & $2.219^{* * * *}$ & $2.111^{* * * k}$ & $2.214^{k * \ldots * x}$ \\
\hline & $(0.312)$ & $(0.317)$ & $(0.313)$ & $(0.317)$ \\
\hline \multirow[t]{2}{*}{ Age of household head } & $0.021^{*}$ & 0.013 & $0.021^{*}$ & 0.014 \\
\hline & $(0.011)$ & $(0.011)$ & $(0.011)$ & $(0.011)$ \\
\hline \multirow{2}{*}{$\begin{array}{l}\text { Number of females (10-64 } \\
\text { yo) }\end{array}$} & $0.310^{\text {kntkik }}$ & $0.201^{*}$ & $0.306^{\text {*ntwk }}$ & $0.200^{*}$ \\
\hline & $(0.117)$ & $(0.121)$ & $(0.117)$ & $(0.120)$ \\
\hline \multirow[t]{2}{*}{ Number of males (10-64 yo) } & $0.523^{\text {***ke }}$ & $0.367^{* * * *}$ & $0.527^{\text {**kk }}$ & $0.376^{\text {*****}}$ \\
\hline & $(0.102)$ & $(0.115)$ & $(0.102)$ & $(0.115)$ \\
\hline \multirow{2}{*}{$\begin{array}{l}\text { Number of children }(<10 \\
\text { yo) }\end{array}$} & 0.093 & 0.047 & 0.101 & 0.056 \\
\hline & $(0.063)$ & $(0.064)$ & $(0.064)$ & $(0.065)$ \\
\hline \multirow[t]{2}{*}{ Number of elderly ( $>64$ yo) } & -0.193 & -0.322 & -0.199 & -0.327 \\
\hline & $(0.288)$ & $(0.295)$ & $(0.285)$ & $(0.292)$ \\
\hline \multirow[t]{2}{*}{ Ramadan } & $3.529^{* x+k}$ & $3.535^{* * * *}$ & $3.389^{* * x+k}$ & $3.382^{\text {k****k }}$ \\
\hline & $(0.692)$ & $(0.698)$ & $(0.686)$ & $(0.690)$ \\
\hline \multirow[t]{2}{*}{ Located in a valley } & 0.146 & -0.084 & 0.270 & 0.038 \\
\hline & $(0.597)$ & $(0.603)$ & $(0.580)$ & $(0.586)$ \\
\hline Total land cultivated (acres) & $0.018^{*}$ & -0.012 & $0.018^{*}$ & -0.010 \\
\hline & $(0.011)$ & $(0.016)$ & $(0.011)$ & $(0.016)$ \\
\hline Wealth Index (II quintile) & $0.798^{*}$ & 0.545 & $0.753^{*}$ & 0.511 \\
\hline & $(0.427)$ & $(0.438)$ & $(0.424)$ & $(0.434)$ \\
\hline Wealth Index (III quintile) & $1.932^{\text {*xike }}$ & $1.588^{k * * * *}$ & $1.884^{\text {****k }}$ & $1.560^{* * * *}$ \\
\hline & $(0.460)$ & $(0.478)$ & $(0.456)$ & $(0.473)$ \\
\hline Wealth Index (IV quintile) & $2.919^{* * * k x}$ & $2.709^{k+k x k}$ & $2.878^{* \ldots * k}$ & $2.688^{* \ldots * k}$ \\
\hline & $(0.480)$ & $(0.498)$ & $(0.478)$ & $(0.495)$ \\
\hline Wealth Index (V quintile) & $6.713^{\text {*⿻*kik }}$ & $6.485^{* * * k}$ & $6.585^{* * \ldots k k}$ & $6.383^{* * * * *}$ \\
\hline & $(0.629)$ & $(0.645)$ & $(0.628)$ & $1.749^{* * *}$ \\
\hline Provinces (34) & $\mathrm{Y}$ & $\mathrm{Y}$ & $\mathrm{Y}$ & $\mathrm{Y}$ \\
\hline Durbin-Wu-Hausman test & & $5.05^{* * \ldots k}$ & & $5.14^{\text {ktkktk}}$ \\
\hline $\begin{array}{l}\text { F-Test on sig. of instrument } \\
\text { (CDI) }\end{array}$ & & $197.82^{\text {***k }}$ & & $196.48^{* * * k}$ \\
\hline $\begin{array}{l}\text { F-Test on sig. of instrument } \\
\quad(\mathrm{CDI} \times \text { lean })\end{array}$ & & $415.99^{* * * *}$ & & $417.80^{* * * *}$ \\
\hline $\begin{array}{l}\text { F-Test on sig. of instrument } \\
\text { (LDI) }\end{array}$ & & $262.62^{* * k \times k}$ & & $258.08^{* * * * *}$ \\
\hline $\begin{array}{l}\text { F-Test on sig. of instrument } \\
\quad(\text { LDI } \times \text { lean })\end{array}$ & & $404.52^{* \star * k}$ & & $405.98^{* * * k}$ \\
\hline Wald chi2 & $100.06^{\text {vkk*x}}$ & $4454.28^{* * * k *}$ & $96.52^{\text {k*k:k}}$ & $4502.96^{* * * * x}$ \\
\hline Adjusted R-square & 0.36 & 0.34 & 0.36 & 0.34 \\
\hline Observations & 14,079 & 14,079 & 14,079 & 14,079 \\
\hline
\end{tabular}

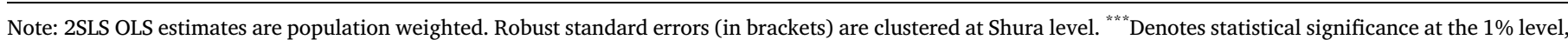
${ }^{* * *}$ at $5 \%$ level and ${ }^{*}$ at $10 \%$ level. 
Appendix B. Supplementary material

Supplementary data to this article can be found online at https://doi.org/10.1016/j.foodpol.2019.101731.

\section{References}

Arimond, M., Ruel, M.T., 2004. Dietary diversity is associated with child nutritional status: evidence from 11 demographic and health surveys. J. Nutr. 134, 2579-2585.

Balarajan, Y., Ramakrishnan, U., Özaltin, E., Shankar, A.H., Subramanian, S.V., 2011. Anaemia in low-income and middle-income countries. Lancet 378, 2123-2135.

Becquey, E., Delpeuch, F., Konaté, A.M., Delsol, H., Lange, M., Zoungrana, M., MartinPrevel, Y., 2012. Seasonality of the dietary dimension of household food security in urban Burkina Faso. Br. J. Nutr. 107 (12), 1860-1870.

Behrman, J.R., 1997. Intrahousehold distribution and the family. In: Rosenzweig, M.R., Stark, O. (Eds.), Handbook of Population and Family Economics. North-Holland, Amsterdam, pp. 125-187.

Black, R.E., Victora, C.G., Walker, S.P., Bhutta, Z.A., Christian, P., De Onis, M., Uauy, R., 2013. Maternal and child undernutrition and overweight in low-income and middleincome countries. Lancet 382, 427-451.

Caspi, C.E., Sorensen, G., Subramanian, S.V., Kawachi, I., 2012. The local food environment and diet: a systematic review. Health Place 18 (5), 1172-1187.

Chege, C.G.K., Andersson, C.I.M., Qaim, M., 2015. Impacts of supermarkets on farm household nutrition in Kenya. World Dev. 72, 394-407.

Central Statistics Organisation, 2014. National Risk and Vulnerability Assessment (NRVA) 2011-12. Afohanistan Living Condition Survey. CSO, Kabul (Afghanistan).

Central Statistics Organisation, 2016. Afghanistan Living Conditions Survey 2013-14: National Risk and Vulnerability Assessment. CSO, Kabul (Afghanistan).

Devereux, S., Sabates-Wheeler, R., Longhurst, R., 2013. Seasonality, Rural Livelihoods and Development. Routledge.

Dillon, A., Kevin, M., Gbemisola, O., 2015. Agricultural production, dietary diversity and climate variability. J. Dev. Stud. 51 (8), 976-995.

Flores-Martinez, A., Zanello, G., Shankar, B., Poole, N., 2016. Reducing anemia prevalence in Afghanistan: socioeconomic correlates and the particular role of agricultural assets. PLoS ONE 11 (6) e0156878.

Herforth, A., 2010. Promotion of Traditional African Vegetables in Kenya and Tanzania: A Case Study of An Intervention Representing Emerging Imperatives in Global Nutrition. Cornell University, Ithaca, NY.

Hirvonen, K., Taffesse, A.S., Hassen, I.W., 2016. Seasonality and household diets in Ethiopia. Public Health Nutr. 19 (10), 1723-1730.

Hirvonen, K., Hoddinott, J., 2017. Agricultural production and children's diets: evidence from rural Ethiopia. Agric. Econ. 48, 469-480.

Hoddinott, J., Headey, D., Dereje, M., 2015. Cows, missing milk markets, and nutrition in Rural Ethiopia. J. Dev. Stud. 51, 958-975.

Holloway, G., Shankar, B., Rahman, S., 2002. Bayesian spatial probit estimation: a primer and an application to HYV rice adoption. Agric. Econ. 27 (3), 383-402.

IFPRI, 2015. Global Nutrition Report 2015: Actions and Accountability to Advance Nutrition and Sustainable Development. International Food Policy Research Institute, Washington, DC.

Jones, A.D., Shrinivas, A., Bezner-Kerr, R., 2014. Farm production diversity is associated with greater household dietary diversity in Malawi: findings from nationally representative data. Food Policy 46, 1-12.

Kennedy, G., Ballard, T., Dop, M.C., 2011. Guidelines for Measuring Household and Individual Dietary Diversity. Food and Agriculture Organization of the United Nations, Rome (Italy).

Koppmair, S., Kassie, M., Qaim, M., 2017. Farm production, market access and dietary diversity in Malawi. Public Health Nutr. 20 (2), 325-335.

Kumar, N., Harris, J., Rawat, R., 2015. If they grow it, will they eat and grow? Evidence from Zambia on agricultural diversity and child undernutrition. J. Dev. Stud. 51 (8), 1060-1077.
LaFave, D., Peet, E., Thomas, D., 2013. Are Rural Markets Complete? Prices, Profits and Recursion. Mimeo. < http://web.colby.edu/drlafave/files/2012/08/farmprices 15jan13.pdf $>$.

Levitt, E., Kostermans, K., Laviolette, L., Mboya, N., 2011. Malnutrition in Afghanistan: Scale, Scope, Causes, and Potential Response. World Bank Publications. Washington, DC: (US).

Li, H., Zhao, J., 2018. Rebound effects of new irrigation technologies: the role of water rights. Am. J. Agric. Econ. 100 (3), 786-808.

Meng, E., Smale, M., Bellon, M., Grimanelli, D., 1998. Definition and measurement of crop diversity for economic analysis. Farmers Gene Banks and Crop Breeding: Economic Analyses of Diversity in Wheat Maize and Rice. Kluwer, Boston, MA (US).

Ministry of Public Health and UNICEF, 2013. National Nutrition Survey Afghanistan (2013): Survey Report. Afghanistan Ministry of Public Health, Kabul.

Nixon, H., 2008. Subnational State-Building in Afghanistan. Afghanistan Research and Evaluation Unit, Afghanistan (Kabul).

Olney, D.K., Talukder, A., Iannotti, L.L., Ruel, M.T., Quinn, V., 2009. Assessing impac and impact pathways of a homestead food production program on household and child nutrition in Cambodia. Food Nutr. Bull. 30 (4), 355-369.

Poole, N. et al., 2016. Stakeholder Perceptions of Agriculture and Nutrition Policies and Practice: Evidence from Afghanistan. LANSA Working Paper Number 9. Chennai, India, Leveraging Agriculture for Nutrition in South Asia (LANSA), MS Swaminathan Research Foundation.

Rawlins, R., Pimkina, S., Barrett, C.B., Pedersen, S., Wydick, B., 2014. Got milk? The impact of Heifer International's livestock donation programs in Rwanda on nutritional outcomes. Food Policy 44, 202-213.

Remans, R., DeClerck, F.A.J., Kennedy, G., Fanzo, J., 2015. Expanding the view on the production and dietary diversity link: scale, function, and change over time. Proc. Natl. Acad. Sci. USA 112, E6082.

Rutstein, S.O., Kiersten, J., 2004. The DHS Wealth Index. Calverton, Maryland (USA).

Sibhatu, K.T., Krishna, V.V., Qaim, M., 2015a. Production diversity and dietary diversity in smallholder farm households. Proc. Natl. Acad. Sci. 112 (34), 10657-10662.

Sibhatu, K.T., Krishna, V.V., Qaim, M., 2015b. Reply to Remans et al.: strengthening markets is key to promote sustainable agricultural and food systems. Proc. Natl. Acad. Sci. USA 112 (45), E6083.

Sibhatu, K.T., Qaim, M., 2017. Rural food security, subsistence agriculture, and seasonality. PLoS ONE 12, e0186406.

Sibhatu, Kibrom T., Qaim, Matin, 2018. Review: Meta-analysis of the association between production diversity, diets, and nutrition in smallholder farm households. Food Policy 77, 1-18.

Singh, I., Squire, L., Strauss, J., 1986. A survey of agricultural household models: recent findings and policy implications. World Bank Econ. Rev. 1 (1), 149-179.

Smith, L.C., Haddad, L., 2015. Reducing child undernutrition: past drivers and priorities for the post-MDG Era. World Dev. 68, 180-204.

Taylor, J.E., Adelman, I., 2003. Agricultural household models: genesis, evolution, and extensions. Rev. Econ. Household 1, 33-58.

Turner, R., et al., 2013. Agriculture for improved nutrition: the current research landscape. Food Nutr. Bull. 34 (4), 369-377.

World Bank, 2014. Islamic Republic of Afghanistan Agricultural Sector Review: Revitalizing Agriculture for Economic Growth, Job Creation and Food Security. Washington DC, World Bank. Available: https://openknowledge.worldbank.org/ handle/10986/21733. License: CC BY 3.0 IGO.

Wiggins, S., Keats, S., 2013. Smallholder agriculture's contribution to better nutrition. Afr. J. Food Agric. Nutr. Dev. 1, 13(3).

WFP, 2008. Food Consumption Analysis: Calculation and Use of the Food Consumption Score in Food Security Analysis. World Food Programme, Rome (Italy) 